\title{
Hydrogel and membrane scaffold formulations of Frutalin (breadfruit lectin) within a polysaccharide galactomannan matrix have potential for wound healing
}

Felipe Domingos de Sousa ${ }^{\mathrm{a}, \mathrm{b} *}$, Pedrinha Diógenes Vasconselos ${ }^{\mathrm{a}}$, Ayrles Fernanda Brandão da Silva ${ }^{\mathrm{c}}$, Erika Freitas Mota $^{\mathrm{d}}$, Adriana da Rocha Tomée, Francisco Rogênio da Silva Mendes ${ }^{\mathrm{a}}$, Anida Maria Moraes Gomes ${ }^{\mathrm{f}}$, David J. Abraham $^{\mathrm{g}}$, Xu Shiwen ${ }^{\mathrm{g}}$, James S. Owen ${ }^{\mathrm{c}}$, Marcos Roberto Lourenzoni ${ }^{\mathrm{h}}$, Adriana Rolim Campos ${ }^{\mathrm{a}}$, Ana Cristina de Oliveira Monteiro-Moreira ${ }^{\mathrm{a}}$, Renato de Azevedo Moreira ${ }^{\mathrm{a}, \mathrm{b}}$.

${ }^{a}$ Northeast Biotechnology Network (RENORBIO), Centre of Experimental Biology (Nubex), University of Fortaleza (UNIFOR). CEP 60811905, Fortaleza-Ceará, Brazil

${ }^{\mathrm{b}}$ Department of Biochemistry and Molecular Biology, Federal University of Ceará (UFC), Campus do Pici s/n, Bloco 907, CEP 60451-970, Fortaleza-Ceará, Brazil

${ }^{\mathrm{c}}$ Institute of Liver and Digestive Health, Division of Medicine, University College London, Royal Free Campus, London, NW3 2PF, UK

${ }^{\mathrm{d}}$ Department of Biology, Federal University of Ceará (UFC), Campus do Pici s/n, Bloco 906, CEP 60451-970, Fortaleza-Ceará, Brazil

' State University of Ceará, Campus of Itaperi, CEP 60.740-000, Fortaleza, Ceará, Brazil

${ }^{f}$ Department of Organic and Inorganic Chemistry, Polymer Laboratory, Federal University of Ceará, PO Box 6021, Fortaleza, Brazil

${ }^{g}$ Centre for Rheumatology and Connective Tissue Diseases, University College London, Royal Free Campus, London, NW3 2PF, UK

${ }^{\mathrm{h}}$ Fiocruz, Fundação Oswaldo Cruz - Ceará, Drugs and Biopharmaceuticals Development Group: Evolution, in silico and in vitro of Biomolecules. CEP 60175-047 Fortaleza, CE, Brazil

* Corresponding author at: Centre of Experimental Biology (Nubex), University of Fortaleza (UNIFOR), Fortaleza-Ceará, Brazil. E-mail address: fdsousa@yahoo.com.br ; Telephone: +55-85-3477-3803.

\begin{abstract}
Plant lectins are carbohydrate-binding proteins, which can interact with cell surfaces to initiate both inflammatory and antiinflammatory pathways, as well as immunomodulatory functions. Here, we extracted, purified and part-characterized the bioactivity of four seed lectins, Jacalin, Frutalin, DAL and PNA, before evaluating their potential for wound healing in cultured human skin fibroblasts. Only Frutalin stimulated fibroblast migration in vitro, prompting further studies which established its low cytotoxicity (unaffected fibroblast viability at $\leq 1 \mathrm{mg} / \mathrm{mL}$ ) and interaction with TLR-4 receptors. The lectin also increased p-ERK expression, a marker of fibroblast proliferation, and stimulated IL-6 secretion. The in vivo potential of Frutalin for wound healing was then assessed in hybrid combination with the polysaccharide galactomannan, purified from Caesalpinia pulcherrima seeds, using both hydrogel formulations and membrane scaffolds (lyophilized hydrogel). Physicalchemical characterization of the hybrid showed that lectin-galactomannan interactions increased the pseudoplastic behaviour of solutions, reducing viscosity and increasing Frutalin's concentration. Furthermore, infrared spectroscopy revealed $-\mathrm{OH}$ band displacement (from 3350 to $3595 \mathrm{~cm}^{-1}$ ), likely caused by interaction of Frutalin with galactose residues present on galactomannan chains, while average membrane porosity was $100 \mu \mathrm{m}$, sufficient to ensure water vapor permeability. The healing activities of each hybrid material at three different Frutalin to galactomannan ratios were then tested in a surgical mouse model of cutaneous excisional wound repair. Accelerated angiogenesis and increased fibroblast and keratinocyte proliferation were observed with the optimal hybrid recovering the lesioned area after 11 days. Our findings indicate Frutalin as a biomolecule with potential for tissue repair, regeneration and chronic wound healing.
\end{abstract}

Keywords: Frutalin, TLR-4, Caesalpinia pulcherrima, Biomaterials

\section{Statement of Significance}

This research addresses the urgent unmet biomedical need of effective treatment for wound healing. We evaluated the combination of Frutalin/galactomannan-based hydrogels and membrane scaffolds as potential therapeutics for difficult to heal skin lesions. We worked on biomaterial design and characterization, fabrication development, and both in vitro and in vivo bioassessment. Our approach was multidisciplinary, integrating biophysical investigations with in vitro models to understand biocompatibility and potential for cell proliferation (stimulation of fibroblast motility, promoting migration and affecting fibroblast physiology) and for regulating protein expression. Finally, histological evaluations were undertaken in a preclinical model of excisional wound repair to understand safety and effectiveness of the developed biomaterials. Our data support further development of Frutalin/galactomannan matrices for wound dressing and healing. 


\section{Graphical Abstract}

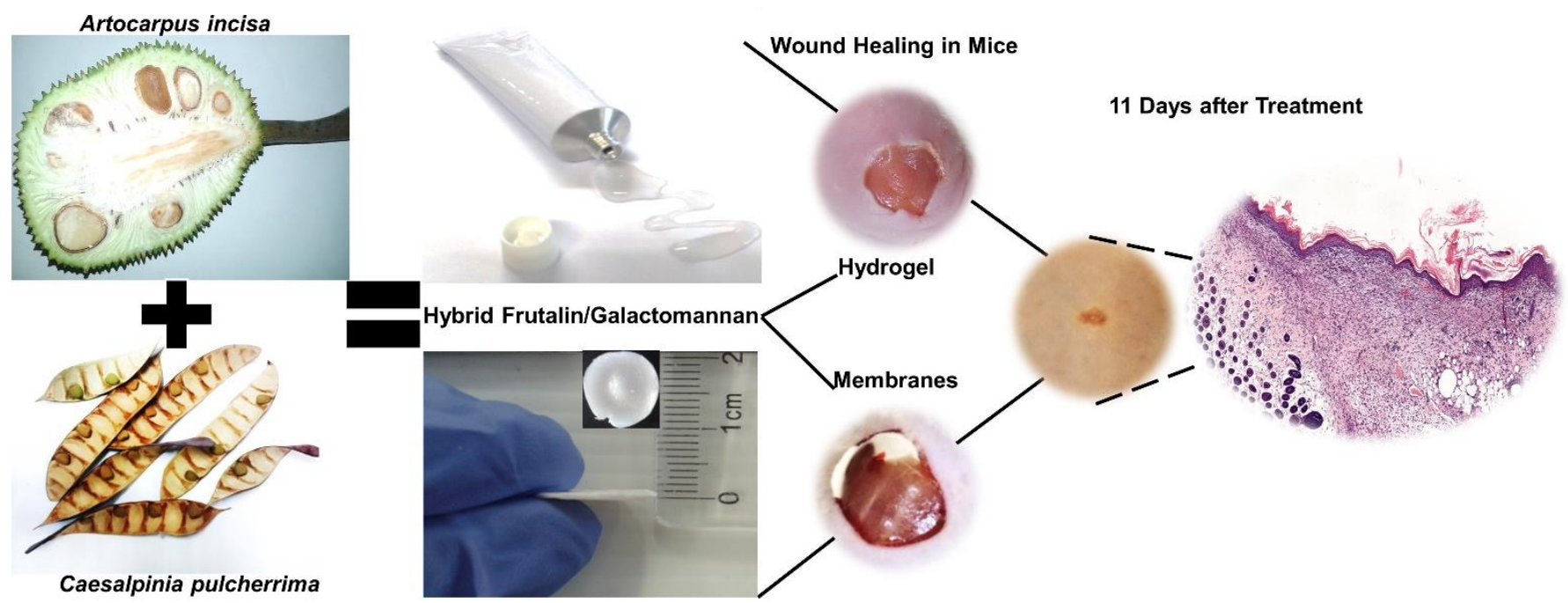

\section{Introduction}

Lectins are carbohydrate-binding proteins or glycoproteins widely distributed in nature, playing different biological roles such as molecule recognition, vegetative storage proteins and plant defense mechanisms [1]. Legume lectins are models for studying protein-carbohydrate interactions [2] and their specificities in detecting cell surface glycoproteins make them a paradigm in protein-carbohydrate recognition [3]. Frutalin is a tetrameric lectin isolated from Artocarpus incisa seeds, popularly known as breadfruit. It has high affinity for $\alpha$-D-galactose moieties within complex carbohydrate structures and belongs to the Jacalin-related lectin (JRL) family, or more precisely its galactose-ligand subfamily with Jacalin itself able to bind both $\alpha$-D-galactose and $\beta$-D-galactose. Several biological activities are attributed to Frutalin: it is cytotoxic to tumor cells [4] and, as we have shown, chemotactic for rat and human neutrophils, a potent mitogen of human lymphocytes [5], an inhibitor of orofacial nociception in acute and chronic pain mediated by TRPA1, TRPV1 and TRPM8 receptors [6], and a protector against ethanol-induced gastric lesions [7], as well as having antidepressant-like actions [8].

Another lectin we have characterized from the tribe Phaseolae, subtribe Diocleinae, is the Dioclea altissima seed lectin (DAL), which has specificity both for D-mannose and D-glucose [9]. Although rational classification of lectins is based on monosaccharide specificity, individual members within a group may still exhibit dissimilar interactions with cell membranes and glycoconjugates, leading to differential biological actions [9]. Peanut agglutinin (PNA), a lectin from Arachis hypogaea seeds, is also of interest as it specifically binds Gal- $\beta(1-3)$-GalNAc sequences to allow its wide use in cell biology and biochemistry [10].

Polysaccharides constitute another class of biomolecules and include the galactomannans, hemicelluloses found mainly in endosperm of legume seeds. They are considered storage not structural polysaccharides and help accumulate water during plant development. Galactomannans are polymers with a $\beta$-(1-4)-D-mannose backbone and D-galactose side units linked $\alpha-(1-6)$ [11]. The mannose:galactose ratio can vary 5 -fold, depending on the species and extraction method, affecting the solubility and rheology of solutions [12]. Viscous solutions can form even at low concentrations, a property used in the food industry for water retention and to act as stabilizers, thickeners, gelling agents, and emulsifiers, as well as formation of films or coatings [13]. Indeed, polysaccharide-containing systems are now receiving wider global interest due to their structural features, rheology and general applicability, whilst having critical advantages over synthetic polymers, including abundance and production by renewable sources and negligible biological toxicity [14-16]. Hence, ecological production of galactomannans is a lucrative activity in many regions of the world, from initial planting and harvesting of seeds to industrial polysaccharide production [16-19].

Moreover, natural biomolecules are increasingly relevant for biomedical applications, most notably tissue engineering. Within this discipline is formulation of new treatment strategies for wound repair, both to protect from damage and to accelerate lesion healing [20,21]. The healing process involves a carefully orchestrated sequence of biochemical and cellular events, all directed to tissue repair; it involves chemical signals, organization of cells and restitution of extracellular matrix. Although healing by primary intention of a clean, uninfected wound without tissue loss invariably has good outcomes, the repair process by secondary intention with extensive cell and tissue loss is more complex and problematic [22]; it is here that biomaterials can bring the greatest benefits.

The aim of our study, therefore, was to assess modulation of excision wound repair by treating with a plant lectin, selected for optimal healing properties, in combination with galactomannan as an immobilization matrix. Plant lectins 
from Artocarpus integrifolia (Jacalin), Artocarpus incisa (Frutalin), Arachis hypogaea (PNA) and Dioclea altissima (DAL) were chosen for the initial screen, as each has different carbohydrate-recognition specificity. They were extracted from seeds, purified and assayed for bioactivity, including use of cultured fibroblasts. Frutalin proved most effective in fibroblast migration assays and hence was combined with galactomannan to obtain hydrogels and also membrane scaffolds; both formulations were then evaluated for dermal wound healing in mice bearing punch biopsy excisional wounds.

\section{Materials and methods}

\subsection{Materials}

Artocarpus incisa, Artocarpus integrifolia and Dioclea altissima seeds were collected within metropolitan Fortaleza, Ceará, while Arachis hypogaea seeds purchased at the local São Sebastião Market. All the seeds were selected and peeled. Arachis hypogaea seeds were delipidated, and apart from Dioclea altissima, all the others were dehydrated with acetone to obtain a flour of grain size $\sim 0.4 \mathrm{~mm}$. Caesalpinia pulcherrima seeds were also collected in metropolitan Fortaleza, cleaned and stored at room temperature until further use. A representative specimen was deposited in Herbarium Prisco Bezerra (EAC), Federal University of Ceará, under no. 56367.

\subsection{Extraction and purification}

\subsubsection{Lectins}

Crude extracts of A. incisa (breadfruit), A. integrifolia (jackfruit), A. hypogaea (peanuts) and D. altissima were prepared by stirring for $30 \mathrm{~min}$ in $0.15 \mathrm{M} \mathrm{NaCl}$ (flour: saline, $1: 10)$, centrifuging for $30 \mathrm{~min}$ at $10,000 x g\left(4{ }^{\circ} \mathrm{C}\right)$ and filtered. The obtained extracts were submitted to the affinity chromatography: Frutalin and Jacalin were isolated on DGalactose-agarose affinity columns (Pierce®); PNA on a lactose-agarose column (Sigma); and DAL on a dextran (Sephadex G50) column. The eluted lectin fractions were collected, dialysed against distilled water and lyophilized. Purity was confirmed by SDS-PAGE, while functional activity was assessed by a routine hemagglutination assay to measure Minimal Concentration for Agglutination (MCA) [23,24].

\subsubsection{Galactomannan}

C. pulcherrima seeds were milled, and after manually separating endosperms from cotyledon and husk they were immersed in boiling $96 \%$ ethanol for 10 min to deactivate enzymes. The endosperms were kept in distilled water (w:v, 1:5) at $7{ }^{\circ} \mathrm{C}$ overnight, then water $(10 \mathrm{vol})$ added before blending at $500 \mathrm{rpm}$ to obtain a viscous solution. After filtration in a nylon net filter $(180 \mu \mathrm{m}$ pore size $)$, galactomannan was precipitated by addition of $96 \%$ ethanol ( $2 \mathrm{vol})$, collected and dispersed in acetone $(1: 5, \mathrm{w}: \mathrm{v})$ for $15 \mathrm{~min}$, followed by airflow drying to produce a powder. This was suspended in water (1:100, w:v) and ethanol precipitation repeated, before milling the purified polysaccharide and sieving $(0.125 \mathrm{~mm}$ mesh) [17].

The total protein content of galactomannan was estimated by the Kjeldahl method for total nitrogen content [25] using the conversion factor of $\mathrm{N} \times 5.7$. For monosaccharide composition, ${ }^{1} \mathrm{H} \mathrm{NMR}$ analysis was performed on galactomannan dissolved $(10 \mathrm{mg} / \mathrm{ml})$ in high quality $\mathrm{D}_{2} \mathrm{O}(99.96 \% \mathrm{D})$. Spectra were recorded at $85^{\circ} \mathrm{C}$ on an $\mathrm{Avance}$ DRX-500 Bruker Spectrometer equipped with a process controller, and using a relaxation delay of $1 \mathrm{~s}$ and a pulse width of 90 to reach conditions for quantitative analysis. The ${ }^{1} \mathrm{H}$ anomeric proton signals for mannose (at 4.00 and $4.72 \mathrm{ppm}$ on ${ }^{1} \mathrm{H}$ ) and galactose (at 4.99 and $5.00 \mathrm{ppm}$ on ${ }^{1} \mathrm{H}$ ) were integrated, using Varian VNMRJ 4 software, to estimate their relative proportions in the sample.

\subsection{Microorganism agglutination, $M I C$ and $M B C$}

Candida albicans (ATCC 10231), Escherichia coli (ATCC 8739), Klebsiella pneumoniae (ATCC 13883), Pseudomonas aeruginosa (ATCC 9027), and Staphylococcus aureus (ATCC 6538) strains were supplied by the Laboratory of Microbiological Quality Control, University of Fortaleza (UNIFOR) and cultured in brain heart infusion (BHI) broth at $35 \pm 2{ }^{\circ} \mathrm{C}$ for $24 \mathrm{~h}$. The microorganisms were collected by centrifugation $(1000 x g)$ and suspended in BHI broth with O.D. $\left(\lambda_{620)}=0.080\right.$ to $0.100,\left(1.5 \times 10^{8} \mathrm{CFU} / \mathrm{mL}\right)$. Strain agglutination was performed on glass slides using 2 $\mathrm{mg} / \mathrm{mL}$ lectin solutions and the microorganism suspensions $(20 \mu \mathrm{L}$ lectin $+20 \mu \mathrm{L}$ microorganism $)$. The slides were shaken in circles and left for $5 \mathrm{~min}$ at room temperature, subjected to Gram staining and observed visually under $20 \mathrm{x}$ magnification by optical microscopy.

Minimum Inhibitory Concentration (MIC) and Minimum Bactericidal Concentration (MBC) were determined by the 96-well plate microdilution method according to The Clinical \& Laboratory Standards Institute [26]. Serial dilutions of lectins (initially $1 \mathrm{mg} / \mathrm{mL}$ ) were made in saline and $50 \mu \mathrm{L}$ added to each well, followed by $100 \mu \mathrm{L}$ BHI broth, $50 \mu \mathrm{L}$ microorganism inoculums $\left(1.5 \times 10^{5} \mathrm{CFU} / \mathrm{mL}\right)$ and resazurin solution $(10 \mu \mathrm{L})$. After incubation for $24 \mathrm{~h}$ at $37{ }^{\circ} \mathrm{C}$, sample growth was monitored by resazurin color change; the lowest concentration without visible growth was defined as MIC. For MBC, $5 \mu \mathrm{L}$ aliquots were aseptically removed from MIC wells without visible turbidity, seeded onto 
Müeller Hinton agar (Merck®) and incubated for $24 \mathrm{~h}$ at $37{ }^{\circ} \mathrm{C}$. MBC was defined as the lowest lectin concentration, which inhibited $99.99 \%$ or more of the initial inoculum. Each measurement was performed in quadruplicate.

\subsection{TLR4 reporter assay}

TLR4 stimulation by the lectins was monitored using HEK-Blue ${ }^{\mathrm{TM}}$ hTLR4, obtained by co-transfection of the hTLR4 gene, the MD-2/CD14 co-receptor genes and a secreted embryonic alkaline phosphatase (SEAP) reporter gene into HEK293 cells (InvivoGen (B). The medium waks supplemented with $50 \mu \mathrm{g} / \mathrm{mL}$ of each lectin and levels of SEAP were determined with HEK-Blue ${ }^{\mathrm{TM}}$ detection over the time of $24 \mathrm{~h} .100 \mathrm{ng} / \mathrm{mL}$ of LPS was used as agonist.

\subsection{In vitro assays using fibroblasts}

Normal human skin fibroblasts (NHSF) were derived from dermal biopsies of healthy donors and cultured at the Royal Free Campus, UCL (studies performed under Research Ethics Committee Protocol Approval Number: REC/6398). Cells were grown, and experiments conducted, in Dulbecco's Modified Eagle's Medium (GIBCO, USA) high-glucose medium supplemented with $10 \%$ fetal bovine serum (GIBCO, USA) and $1 \%$ penicillin-streptomycin by incubation at $37{ }^{\circ} \mathrm{C}$ in $5 \% \mathrm{CO}_{2}$. In experiments, fibroblasts were used between passages 2 and 6 to avoid phenotypic changes during subculture.

\subsubsection{Cell viability}

NHSF cells were seeded at $5 \times 10^{3}$ per well in 96-well plates. After adhesion and recovery for $12 \mathrm{~h}$, cells were treated with each of the four lectins in the concentration range of $1-1000 \mu \mathrm{g} / \mathrm{mL}$ for $72 \mathrm{~h}$, following which cell viability was measured by the PrestoBlue ${ }^{\circledR}$ resazurin-based reagent. Results were expressed as a percentage compared to untreated cells. Statistical significance was assessed by ANOVA one-way analysis of variance, followed by the Bonferroni test for multiple means. The level of significance was determined as $\mathrm{p}<0.05$ using GraphPad Prism software, version 6.00, La Jolla California USA.

\subsubsection{Fibroblast migration assays}

The ability of lectins to induce NHSF cell migration into a denuded and wounded cell monolayer area was assessed using the scratch wound assay [24,27]. Fibroblasts were seeded into 6-well plates and grown overnight to confluence before creating a $1 \mathrm{~mm}$ linear scratch in each well. After removal of growth media, triplicate test wells received 50 $\mu \mathrm{g} / \mathrm{mL}$ lectin and $5 \mu \mathrm{g} / \mathrm{mL}$ mitomycin-C (to prevent cell proliferation), while control wells received vehicle alone. Scratched areas were photographed at $0,8,12,24$ and $48 \mathrm{~h}$ post-treatment and data analyzed with ImageJ $1.42 \mathrm{q}$ software (National Institutes for Health, USA) to measure the distance travelled by cells into the wound. The percentage of cell migration at each time was calculated as follows:

\section{Scratch closure rate $=\left[\left(D_{0}-D_{n} / D_{0}\right] \times 100 \%\right.$}

where $D_{0}$ is the average initial distance between both sides of the scratch and $D_{n}$ is the average distance between both sides of the scratch at the measured time. Experiments were performed in triplicate in two independent assays.

Of the four lectins, Frutalin showed the greatest closure rate and so was selected for further evaluation by the Boyden Chamber cell migration assay using 24 -well plates with $8 \mu \mathrm{m}$ inserts. Briefly, NHSF fibroblasts $\left(3 \times 10^{5}\right.$ per well) were grown to confluence in the upper chamber and then Frutalin $(50 \mu \mathrm{g} / \mathrm{mL})$ added to the lower chamber; controls were no Frutalin and also equal Frutalin concentrations in both lower and upper chambers. After $24 \mathrm{~h}$ exposure, upper surface cells were removed by sterile swab, and those migrating to the lower compartment fixed with methanol and stained with $0.1 \%$ crystal violet. Migrated cells were counted in 5 randomized fields per specimen under inverted microscope and treatments compared statistically by Student's t-test, $\mathrm{p}<0.05$ using GraphPad Prism software, version 6.00, La Jolla California USA.

\subsubsection{Assessment of fibroblast physiology and IL-6 production}

NHSF fibroblasts were grown overnight in 6-well plates and then medium containing Frutalin $(50 \mu \mathrm{g} / \mathrm{mL})$ added for 0, 0.5, 1, 2, 4 and $24 \mathrm{~h}$; control wells received medium alone. At each time, cells were washed with PBS, then lysed with RIPA buffer (Sigma-Aldrich) supplemented with cOmplete TM Protease Inhibitor Cocktail (Roche) and Phosphatase Inhibitor Cocktails (Sigma-Aldrich). Supernatants were collected by centrifugation (30 min at 10,000 xg, 4 ${ }^{\circ} \mathrm{C}$ ) and, after protein measurement by BCA assay, $10 \mu \mathrm{g}$ samples were separated on NuPAGE ${ }^{\mathrm{TM}} 4-12 \%$ Bis-Tris Protein Gels $(1.0 \mathrm{~mm})$ gel before electrotransfer to polyvinylidene difluoride (PVDF) membranes.

Following incubation with casein blocking buffer for $1 \mathrm{~h}$ to reduce nonspecific interactions, the membranes were incubated with diverse primary antibodies for $12 \mathrm{~h}$ at $4{ }^{\circ} \mathrm{C}$ to assess Frutalin-induced cell changes in cell signaling plus collagen, cytokine and growth factor production. Primary antibodies used and respective dilutions were: anti- $\beta$-tubulin (1: 10000, Abcam, ab6046); Anti-p-IkB- $\beta$ antibody (1: 500, Abcam, ab 7547); Collagen Type I antibody (1: 1000, Millipore, AB758); Anti-p-ERK 1/2(1: 1000, Abcam, 9101s), anti-MyD88 antibody (1: 1000, Abcam, ab2068), antiCTGF (1: 500, Santa Cruz Biotechnology, Sc-14939) and anti-NF-kB p65 antibody (1: 1000, Santa Cruz Biotechnology, sc-8008). Detection was with HRP-conjugated secondary antibodies, the labeled proteins being visualized with an ECL Western Blotting kit (ECL Plus, Amersham, UK) and quantified with Image J software 
(National Institute of Health, USA) by normalization to $\beta$-tubulin. Results were analyzed by Student's t-test, $\mathrm{p}<0.05$ using GraphPad Prism software, version 6.00, La Jolla California USA.

In parallel experiments, NHSF cells were exposed to Frutalin $(50 \mu \mathrm{g} / \mathrm{mL})$ for $24 \mathrm{~h}$ and the culture medium assayed for IL-6 secretion by ELISA using a Quantikine ELISA kit (R\&D Systems, Minneapolis, USA).

\subsection{Molecular docking studies}

We docked Frutalin (PDB id: 4WOG) to the TLR4/MD-2 receptor complex (PDB id: 3FX1) using HADDOCK 2.2 $[28,29]$ to generate an interface model for the interaction. MD-2 is a soluble protein that non-covalently associates with TLR4, but can directly form a complex with LPS in the absence of TLR4 [30]. The NetNGlyc 1.0 Server (http://www.cbs.dtu.dk/services/NetNGlyc/) predicted two glycosylation sites for MD-2, one at Asn8 and the other closer to the TLR4/MD-2 interface at Asn96. Thus, Frutalin may interact with the carbohydrate portion of MD-2 at position 96 and activate TLR4. Residue Asn96 was considered the pivotal anchoring site and residues within a radius $<6.5 \AA$ were considered to maximize the interaction with the lectin. Frutalin is a homotetramer and each monomer was used for docking and evaluation taking into account its carbohydrate-recognition domain (CRD) (Gly25, Tyr146, Trp147 and Asp149) and the Asn96 residue in MD-2. Our protocol undertook three steps of Haddock execution followed by rigid-body docking, flexible-interface docking and the water layer around the TLR4/MD-2 complex $[28,29]$. The best ligand conformation was selected based on the HADDOCK score and the models were clustered at 7.5 $\AA$ A.

\subsection{Hydrogel and membrane scaffold formulations}

\subsubsection{Hydrogels}

A $1.5 \%(w / v)$ solution of $C$. pulcherrima galactomannan in $0.15 \mathrm{M} \mathrm{NaCl}$ was prepared in a Turratec TE102 homogenizer for $10 \mathrm{~min}$ at $18,000 \mathrm{rpm}$, following which $0.1 \%$ cetyltrimethylammonium bromide (CTAB) was added to prevent microbiological growth. This stock solution was designated F0 (galactomannan hydrogel alone; control) and used to prepare the Frutalin formulations, F01, F05 and F10, which contained $0.1,0.5$ and $1.0 \mathrm{mg}$ Frutalin/ g galactomannan hydrogel, respectively. Each hydrogel was then centrifuged for $30 \mathrm{~min}$ at $10,000 \mathrm{xg}$ and $4{ }^{\circ} \mathrm{C}$ to remove insoluble materials and refrigerated until use.

\subsubsection{Microbiological examination}

Quantitative enumeration of mesophilic bacteria and fungi that may grow under aerobic conditions in the hydrogel preparations were evaluated according to the European Pharmacopoeia [31]. Samples of at least 3 subsequent ten-fold dilutions were inoculated in nutrient and Sabouraud-dextrose agar following the pour-plate method. Then, the total viable aerobic count was performed after 7 days of incubation at $30-35^{\circ} \mathrm{C}$ for bacteria and $20-25^{\circ} \mathrm{C}$ for fungi.

\subsubsection{Membrane scaffolds}

The same hydrogel solutions were prepared as described in 2.7.1., but without $0.1 \%$ CTAB. Each solution was distributed in 24-well plates $(1 \mathrm{~g} /$ well) and lyophilized under temperature and pressure ramps (AdVantage 2.0 Bench Top Freeze Dryer, VirTis, SP Scientific) to obtain a more uniform 'spongy membrane'. The resulting membrane scaffolds were designated: MF0 (galactomannan hydrogel alone; control) plus MF01, MF05 and MF10, containing 0.1, 0.5 and $1.0 \mathrm{mg}$ Frutalin/ g galactomannan hydrogel, respectively.

\subsubsection{Hemagglutination assay with the hydrogels and membrane scaffolds}

To verify that our Frutalin-galactomannan formulations retained bioactivity, both hydrogels and membrane scaffolds (dissolved in saline) were tested in routine hemagglutination assays. They also underwent thermostability testing in the $40-100^{\circ} \mathrm{C}$ range to determine the upper temperature at which Frutalin still remains active.

\subsection{Rheology studies}

Mechanical stability studies used a stress-controlled rheometer (Anton Paar MCR 302) housing a circular parallel plate cell with internal diameter (i.d.) $=25 \mathrm{~mm}$ and height $(\mathrm{h})=1 \mathrm{~mm}$ gap between plates. All experiments were conducted at $25{ }^{\circ} \mathrm{C}$ and included stress-strain tests, rotational flow, and oscillatory viscoelastic linear-response measurements. The rheometer was operated in oscillatory mode for stress-strain tests: at a fixed frequency $\omega=10 \mathrm{rad} / \mathrm{s}$ with an externally applied shear strain from 0.01 to $100 \%$, while recording storage (G') and loss (G') moduli. This allows mechanical responses of samples to be assessed from the reversible linear response regime up to the nonlinear region, where the sample structure collapses and flow starts.

The flow study was conducted in continuous steady-state shear rotational mode by varying the shear rate from 1 to $1000 \mathrm{~s}$. Dynamic oscillatory mode studies were done by varying the applied torque/deformation angular frequency from 0.1 to $100 \mathrm{rad} / \mathrm{s}$. The storage $\left(\mathrm{G}^{\prime}\right)$ and loss $\left(\mathrm{G}^{\prime \prime}\right)$ moduli sample responses were recorded during frequency sweeps at $5.0 \%$ fixed strain amplitude, enough to guarantee linear reversible responses. 


\subsection{Physical characterization of membrane scaffolds: FTIR, SEM and WVP}

Membrane scaffolds were ground under liquid $\mathrm{N}_{2}$, mixed with $\mathrm{KBr}$ and their infra-red spectra determined using a Fourier transform infrared spectrometer (IRTracer-100 spectrophotometer, Shimadzu, Japan). Spectra were recorded at room temperature and, on average, 64 scans were made for each sample at a resolution of $4 \mathrm{~cm}^{-1}$ in the range of 400 $4000 \mathrm{~cm}^{-1}$.

Scanning electron microscopy (SEM) for morphology investigations was carried out in the Central Analítica , Federal University of Ceara. Cross-sectional samples of membrane scaffolds were placed on aluminum stubs and splutter coated with gold prior to analysis. Images were captured with a Phillips XL30 SEM operating at an acceleration voltage of $15 \mathrm{keV}$.

Water Vapor Permeability (WVP) was determined gravimetrically according to ASTM E96-95 (1992) protocols [32]. Eight samples were cut from each sponge membrane, each sealed in a permeation cell (a water-containing cup at $100 \% \mathrm{RH} ; 2.337 \times 10^{3} \mathrm{~Pa}$ vapor pressure at $\left.20{ }^{\circ} \mathrm{C}\right)$, and placed in a desiccator with silica gel $\left(0 \% \mathrm{RH} ; 20{ }^{\circ} \mathrm{C}\right)$. The water vapor transferred through the test samples was determined from cup weight loss over time. Steady-state weight loss was reached after $24 \mathrm{~h}$.

\subsection{In vivo studies}

\subsubsection{Animals, surgical procedures and macroscopic analysis}

Swiss albino mice (20-25 g) housed in the animal facility at the University of Fortaleza (UNIFOR) were kept in a controlled environment with free access to water and standard pellet diet (Purina, São Paulo, Brazil). The experimental protocols followed the ethical guidelines of CONCEA (Brazilian Council for the Control of Animal Experimentation) and were approved by the Animal Ethics Committee of UNIFOR under entry number 004/2014.

Mice were anesthetized by intraperitoneal (i.p.) injection of ketamine $(115 \mathrm{mg} / \mathrm{kg})$ and xylazine $(10 \mathrm{mg} / \mathrm{kg})$ hydrochlorides. The dorsal skin of the animals was shaved, cleaned with $1 \%$ iodopovidone and then subjected to a punch biopsy excisional wound with a cutting blade diameter of $10 \mathrm{~mm}$. After recovery from anesthesia, mice were housed individually in disinfected cages and randomized into nine treatment groups (20 animals/each): Control ( $0.15 \mathrm{M}$ $\mathrm{NaCl}$ ), F0, F01, F05 and F10 for the hydrogel formulations and MF0, MF01, MF05 and MF10 for the membrane scaffolds. Administration of $\mathrm{NaCl}$ and hydrogels was done daily with $100 \mu \mathrm{L}$ sample applied over the wound area, whereas membrane scaffolds were implanted under the muscular fascia and left until the end of the experiment. All groups were evaluated 3, 7, 11 and 14 days after excision $(\mathrm{n}=5 \mathrm{mice} / \mathrm{day} /$ group). At each time point, the wound area was measured using images with a metric reference by the ImageJ® program. In addition, wounds were assessed for hyperemia, edema, bleeding, secretion and scab formation. The classification was performed semi-quantitatively according to the intensity, with the following scores used for edema and hyperemia: Absence (0), Light (1), Moderate (2), Intense (3). The presence of inflammatory exudate was classified as serous, bloody or purulent [33].

\subsubsection{Histological microscopic analysis}

For histological examination the wound area was removed surgically from individual anesthetized mice, which then underwent euthanasia. Tissue samples were arranged in cassettes, fixed in 10\% buffered formaldehyde $\mathrm{pH} 7.2$ and then dehydrated in increasing concentrations of ethanol, before diaphanization in xylol and embedding in paraffin wax. Thick $(5 \mu \mathrm{m})$ tissue sections were cut and stained with H\&E as per routine histology. Stained sections were scanned (Scanner panoramic desk, 3DHISTECH) observed using CaseViewer 1.4 software (3DHISTECH Ltd.) and the histopathological properties of each tissue section were assessed by an experienced pathologist, blinded to the experimental groups.

\subsection{Statistical analysis}

All statistics were performed using GraphPad Prism 6 (GraphPad Software Inc.). Statistical significance was assessed by ANOVA one-way analysis of variance, followed by the Bonferroni's test for multiple mean or by KruskalWallis comparisons for median, followed by the Dunns test. The level of significance was considered as $\mathrm{p}<0.05$.

\section{Results}

\subsection{Extraction, purification and characterization of lectins and galactomannans}

The yields of Frutalin, Jacalin, PNA and DAL based on the flour prepared from seeds were $1.56 \%, 1.96 \%, 0.01 \%$ and $1.38 \%$, respectively. Excellent purity was shown by electrophoresis (Supplementary Fig. S1A), while a routine hemagglutination assay confirmed their post-extraction functionality with Jacalin and Frutalin the most potent showing visible agglutination at the lowest concentrations (MCAs of $0.004 \mu \mathrm{g} / \mathrm{mL}$ and $0.015 \mu \mathrm{g} / \mathrm{mL}$, respectively. Additionally, each lectin was able to bind and agglutinate several pathogenic strains involved in many common infections and impaired healing, namely Staphylococcus aureus, Klebsiella pneumoniae, Pseudomonas aeruginosa, 
Escherichia coli and Candida albicans (Fig. 1). On a subjective scale, the degree of agglutination was Jacalin $>$ Frutalin> DAL $>$ PNA.

Despite promoting agglutination of pathogens, no lectin showed bacteriostatic (MIC) or bactericidal (MBC) activities when tested at $\leq 1 \mathrm{mg} / \mathrm{mL}$. As TLR4 plays a key recognition role of LPS in bacteria outer membranes to trigger the innate response, lectins were tested to see if they were capable of stimulating such a receptor. Dose-response curves showed that all lectins activated the TLR4 receptor, with Frutalin and Jacalin having a comparable potency to LPS, used as a control (Fig. 2). Next, we modelled molecular docking between a TLR4/MD-2 complex and the Frutalin homotetramer (A, B, C and D), assembling them in over 180 complexes. The clusters of each monomer presented negative $\mathrm{Z}$-values and were grouped into 10. The 10 clusters with the lowest Z-values represented over $90 \%$ of the water-refined HADDOCK models generated for the monomers. Except for few differences in Z-values for monomer A, all clusters displayed similar orientation. As a tetramer, Frutalin occupies a molecular volume similar to that of TLR4, which based on docking data suggests that the lectin will interact most favorably with the TLR4/MD-2 complex if orientated as illustrated in Fig.3.

Protein contamination of purified $C$. pulcherrima galactomannan was negligible at $0.08 \%$ as judged by total nitrogen content, reflecting the double ethanol precipitation which increased polysaccharide purity. The monosaccharide ratio was determined by NMR and gave a mannose:galactose ratio of 2.36 in this hemicellulose.

\subsection{In vitro assays}

\subsubsection{Cell viability}

Human skin fibroblasts were used to check lectin cytotoxicity. Frutalin presented no toxicity at concentrations below $1000 \mu \mathrm{g} / \mathrm{mL}$. Proliferative effect was observed at concentrations higher than $500 \mu \mathrm{g} / \mathrm{mL}$ for jacalin and $1000 \mu \mathrm{g} / \mathrm{mL}$ for DAL. The opposite effect was observed in PNA, demonstrating reduction of cell viability at concentrations $>500$ $\mu \mathrm{g} / \mathrm{mL}$.

\subsection{Fibroblast migration}

The ability of each lectin to stimulate NHSF migration in vitro was tested at $50 \mu \mathrm{g} / \mathrm{mL}$, as none were toxic to the cells at this concentration. Of the four lectins, only Frutalin significantly outperformed untreated (control) cells; after $48 \mathrm{~h}$ incubation there was $100 \%$ cell migration versus $30 \%$ (Fig. 4A).

To verify this Frutalin potency, NHSF cells were also cultured in Boyden chambers to assess its effect on fibroblast directional migration. Addition of Frutalin $(50 \mu \mathrm{g} / \mathrm{mL})$ to the lower chamber alone significantly stimulated NHSF migration compared to untreated cells, or when compared to Frutalin addition to both chambers (Fig. 4B).

\subsubsection{Fibroblast signal transduction, and matrix, cytokine and growth factor production}

As for migration studies, NHSF cells were incubated with Frutalin $(50 \mu \mathrm{g} / \mathrm{mL})$ and assayed $0.5,1,2,4 \mathrm{and} 24 \mathrm{~h}$ later. Cell proteins were extracted, quantified and changes in cell signalling proteins and collagen, cytokine and growth factor levels measured by Western blot and ELISA. Exposure to Frutalin produced significantly elevated levels of pERK1/2 and MyD88 in NHSF cells, but no change in NFкB (Fig. 5). Cell collagen levels were decreased $24 \mathrm{~h}$ posttreatment, but the amount of collagen secreted into the culture medium was unchanged at each time point.

Levels of IL-6 secreted into the NHSF culture were also assayed and increased five-fold (ng/mL) with addition of Frutalin for $24 \mathrm{~h}(1.88 \pm 0.23$ versus $10.51 \pm 0.10$; $<<0.0001)$. Although IL-6 has a key role in the acute phase response, it is also involved in different signalling pathways, including those stimulating angiogenesis and cell migration. Hence, all following experiments focussed on Frutalin and its healing potential in the development of topical formulations.

\subsection{Hydrogel and spongy membrane scaffold characterization}

Given the known drug delivery properties of galactomannan, we prepared two Frutalin-galactomannan formulations, hydrogels and spongy membrane scaffolds, for in vivo studies to assess whether Frutalin bioactivity for wound healing would be enhanced. Prior to such testing (see 3.4.), we carried out basic biological and physicochemical evaluations. First, we checked both formulations for bacteria, yeast or and fungi contamination, which would be detrimental to in vivo use, employing standard microbiological culture conditions. All plates with varying aliquots of the formulations showed no growth of microorganisms (data not shown), and hence were deemed suitable for mouse wound healing experiments. Second, use of the hemagglutination assay confirmed that Frutalin retained its activity when combined with galactomannan; each formulation (F01, F05 and F10) retained the ability to agglutinate rabbit erythrocytes. Similarly, solubilization of the membrane scaffolds in saline showed the same agglutination capacity. Moreover, both formulations had good thermostability; heating for $5 \mathrm{~min}$ to a limit of $55{ }^{\circ} \mathrm{C}$ showed good retention of hemagglutinating activity (data not shown).

Rheological tests were performed to evaluate how Frutalin influences the behaviour of its viscous galactomannan vehicle. As shown in Figs. 6A and 6B, the flow curves of all samples had a characteristic profile of a pseudoplastic fluid. By submitting the rheological behaviour of the F0, F01, F05 and F10 hydrogels to the power law model, it was evident that increasing the amount of Frutalin led to an increase in fluid pseudoplasty as seen by an increasing behavior index $n$ (Fig. 6B). Indeed, Frutalin decreased the consistency index, which is directly associated to solution viscosity. 
The hydrogels were further subjected to oscillatory tests. The oscillation frequency was kept constant (10 rad/ s), while the amplitude ranged from 0.01 to $100 \%$ to vary angular frequency from 100 to $0.1 \mathrm{rad} / \mathrm{s}$ (Fig. 6C). Increasing Frutalin concentrations in the samples increased the $\mathrm{G}^{\prime}$ moduli, considered the elastic part of the sample. At $25.1 \mathrm{rad} / \mathrm{s}$ angular frequency, $G^{\prime}=G^{\prime \prime}$ for all samples, while from this point onwards $G^{\prime}>G^{\prime \prime}$ with the samples starting to present a solid profile, acquiring gel structural characteristics.

Temperature sweeps ranging from 25 to $100{ }^{\circ} \mathrm{C}$ were used to investigate the viscosity behaviour of each hydrogel with amplitude and frequency kept constant at $5 \%$ and $10 \mathrm{rad} / \mathrm{s}$, respectively. The modulus $\mathrm{G}$ " reached a plateau in the range of 50 to $60{ }^{\circ} \mathrm{C}$ (Fig. 6D), at which point the samples began to undergo structural changes with the drastic decrease in $\mathrm{G}^{\prime \prime}$ directly related to higher concentrations of Frutalin in the galactomannan solution.

The membrane scaffolds MF0, MF01, MF05 and MF10 were analysed by infrared spectroscopy to identify the main functional groups present in the structures through the absorbance peaks as a function of wave number (Fig. 7A). The bands at 825 and $867 \mathrm{~cm}^{-1}$ are related to anomeric configurations $(\alpha$ and $\beta)$ and glycosidic bonds, indicating the presence of $\alpha$-D-galactopyranose units and $\beta$-D-mannopyranose units, respectively, while the $1025 \mathrm{~cm}^{-1}$ band is due to $\mathrm{CH}_{2}$ vibrational torsion. Bands at 1056 and $1093 \mathrm{~cm}^{-1}$ were also noted and attributed to stretching of the primary alcohol $-\mathrm{CH}_{2} \mathrm{OH}$, whereas the $1141 \mathrm{~cm}^{-1}$ band corresponds to angular deformation of $\mathrm{C}-\mathrm{O}$ due to the pyranose ring. Bands in the range 1379 and $1438 \mathrm{~cm}^{-1}$ are due to symmetrical deformations of the $\mathrm{CH}_{2}$ and $\mathrm{COH}$ groups, while the amide I $\left(1652 \mathrm{~cm}^{-1}\right)$ and II $\left(1542 \mathrm{~cm}^{-1}\right)$ bands mainly originate from $\mathrm{C}=\mathrm{O}$ and $\mathrm{N}-\mathrm{H}$ vibrations in proteins. The band around $2137 \mathrm{~cm}^{-1}$, more predominant in membranes containing Frutalin, was attributed to the bond between the $\mathrm{C}$ and $\mathrm{N}$ atoms, when involved in in peptide bonds. The bands at 2920 and $3350 \mathrm{~cm}^{-1}$ correspond to stretches of the $\mathrm{CH}_{2}$ and $\mathrm{OH}$ groups, respectively, with the latter undergoing clear displacement to $3595 \mathrm{~cm}^{-1}$ for each of the Frutalin-containing membrane scaffolds. This Frutalin-dependent displacement was also observed in photomicrographs of the MF0, MF1, MF2 and MF3 membranes (Fig. 7B), presumably because Frutalin interacts to $\mathrm{OH}$ groups presented in the structure of galactomannan matrix.

The Frutalin-galactomannan membrane scaffolds were also compared based on Water Vapor Permeability (WVP). As shown in Fig. S4, there was a significant increase only between MF0 (Frutalin absent) and MF01 (0.1mg Frutalin / g hydrogel) with higher concentrations of Frutalin having no significant effect on WVP.

\subsection{In vivo assays}

\subsubsection{Hydrogel}

Frutalin-galactomannan hydrogels were applied daily to deep excisional skin wounds on mice, who were monitored at four different time points. Edema occurred mildly in all hydrogel-treated groups (F0, F01, F05 and F10) with a median and variation of 1 (0-1) 3 days post-surgery compared to the saline-treated (control) group. Mild hyperemia was seen in all groups (data no shown), but additional signs of exudation were not observed in treatment groups compared to the control. A significant increase in wound contraction was noted 3 days after treatment for groups F0 and F01; this was not observed for the F05 and F10 groups (Supplementary Fig. S5), or seen for the remaining days (7, 11 and 14).

The dynamics of the healing process was followed by histological analysis and was initially marked by an intense inflammatory infiltrate on days 3 and 7, while fibroblast proliferation and the start of total re-epithelialization of the previously ulcerated area was noted from the $11^{\text {th }}$ day. On day 14 it was possible to observe the beginnings of collagen reorganization. For all the groups, the healing process was accompanied by mild congestion, but marked by intense angiogenesis and proliferation of dermal fibroblast-like cells even 3 days post-surgery (Fig. 8).

In comparing individual groups, the application of hydrogels to F0, F01, F05 and F10 all resulted in an ability to modulate and improve the healing process until the $7^{\text {th }}$ day. However, by day 11 only F01 $(0.1 \mathrm{mg}$ of frutalin $/ \mathrm{g}$ of hydrogel) had promoted collagen organization. It appeared that higher concentrations of Frutalin contained within a galactomannan matrix do not enhance or promote further healing as judged by relevant histopathological changes. Although, as described above, there was no clear relation between wound contraction and treatment time or group, the injured tissue did show healing characteristics. Thus, on the $14^{\text {th }}$ day a complete re-epithelization of the F01-treated lesions was observed, increasing the proliferation of keratinocytes. Taken together these data strongly support the potential of Frutalin to aid and accelerate repair processes within injured skin.

\subsubsection{Spongy membrane scaffolds}

The four groups (MF0, MF01, MF05 and MF10) treated with membrane scaffolds did not show significant amounts of edema or hyperemia when compared to the control group. Measurements of wound contraction revealed a significant increase only for the MF05 group on the $3^{\text {rd }}$ day compared to the untreated control group (Supplementary Fig. S6).

When comparing the control mice to those receiving the galactamannan-only membrane (MF0), we observed no relevant histopathological differences (edema, congestion, and inflammatory infiltrate) between the two groups. However, for the Frutalin-containing membrane scaffolds (MF01, MF05 and MF10), the healing process was marked by intense angiogenesis and absence of edema. Moreover, from the $11^{\text {th }}$ day reorganization of the conjunctive matrix with fibroblasts and other fibroblast-like cells, such as fibrocytes was evident, with a mild to moderate inflammatory infiltrate, diffuse, and predominantly lymphocytes (Fig. 9). Nevertheless, when comparing the different amounts of 
Frutalin in the galactomannan scaffold membranes (MF01 vs. MF05 vs. MF10), we did not observe relevant differences in histopathology. A similar finding was noted for the hydrogel-treated groups, suggesting that Frutalin levels higher than those in MF01/ F01 do not further increase healing capacity of excised lesions. On the other hand, the benefits of Frutalin to wound repair and regeneration were clearly evident.

\section{Discussion}

Plant lectins are relatively soluble in saline solutions, making their extraction and isolation by appropriate carbohydrate-affinity chromatography a simple method. Lectin-carbohydrate interactions occur via hydrogen bonds, Van der Waals forces and other hydrophobic forces, allowing easy elution by excess ligand or $\mathrm{pH}$ change. Lectin carbohydrate specificities have important roles in biological recognition phenomena involving cells and proteins, including immunomodulatory properties in different biomedical settings. In general, the different lectins can be grouped into classes based mainly on the "architecture" of their carbohydrate binding site(s), including specificity and 3D structure plus sequence similarities [34].

Mannose, for example, binds to lectins through diverse residues; ConA via Asn and Asp, Galanthus nivalus agglutinin via Asn, Asp, Gln and Tyr, and mannose-binding protein A via Asn and Gln [34]. By contrast, Frutalin is a breadfruit seed glycoprotein with four isoforms modifying a few amino acids. This gives Frutalin multiple-binding character, able to interact with different ligands using the same carbohydrate binding site. However, its highest affinity is for $\alpha$-D-galactose, which we have shown to be anchored by a cavity of four residues (Gly25, Tyr146, Trp147 and Asp149) near the N-terminal of the $\alpha$ chain [35].

Despite much research, biological roles of native lectins are often more speculative than proven. Many consider their main function as species protection, as lectins such as WGA, PNA and SBA inhibit growth and sporulation of fungi including Trichoderma viride, Penicilium notatum and Aspergillus niger [34]. Indeed, a minor breadfruit lectin, Frutackin that binds chitin, has fungicidal activity-[36]. In the microbial world, lectins are often termed as hemagglutinins, adhesins and toxins, serving to link different cell types, and also viruses to cells, via surface carbohydrates [34,37]. Although dietary plant lectins may cause allergies, trigger autoimmune diseases, or limit nutrient uptake [32], their diverse biological activities have potential biomedical applications, including both diagnostics and therapeutics.

Here, we chose four lectins, Jacalin, Frutalin, DAL and PNA based on their different carbohydrate specificities, for wound healing studies. Each was extracted and isolated with high purity (SDS-PAGE analysis) and good bioactivity (hemagglutination assay). Additionally, only PNA showed some toxicity to cultured human skin fibroblasts at levels below $1.0 \mathrm{mg} / \mathrm{mL}$, allowing further evaluation of all lectins in fibroblast migration assays. This in vitro test, routinely employed prior to animal investigations, identified Frutalin as the most potent lectin, an attractive candidate due to its abundance in Artocarpus incisa seeds (our yield was $1.56 \%$ from seed flour) or potential for recombinant synthesis in $P$. pastoris [38]. Our native preparation was pure, the two distinct 12- and 15.5-kDa protein bands consistent with glycosylation differences between molecules, and performed strongly in the hemagglutination assay with an MCA of $0.15 \mathrm{pg} / \mathrm{mL}$.

Inflammatory, fibrogenic and regenerative responses are part of the sequence of events in an injury response system that serves to contain damage and to restore tissue function through recruitment of several types of specialized cells such as platelets and fibroblasts which provide mechanical stability to the wound in short and long terms; phagocytic leukocytes that combat potential pathogens and clear the site of injury from dead cells and debris, and progenitor or stem cells to replace functional epithelium [39]. Once skin is injured, opportunistic microorganisms obtain access to the underlying tissues, causing invasive infections within a wound with subsequent host injury. Then, we studied interaction of our lectins with five pathogenic microorganisms, all common species in opportunistic infections. However, though we showed all four lectins interacted with surfaces of E. coli, S. aureus, K. pneumoniae, P. aeruginosa and $C$. albicans, to promote microorganism agglutination, none was able to inhibit growth or kill a strain. Nonetheless, all lectins activated the TLR-4 receptor, a key player in detection of invading pathogens through several pattern-recognition mechanisms and regulation of the immune system [30]. There is substantial diversity in the TLR4 cellular expression pattern and tissue distribution in the different mammalian species, as humans, mice, rats, rabbits, and other ones. In mice, TLR4 is expressed in myeloid subsets (monocytes, macrophages, granulocytes, dendritic cells) and lymphoid subsets [40]. Specific TLRs activation and/ or conditions that affect TLR expression are key to whether TLR promotes or inhibits wound healing processes [41]. Frutalin as a multiple-binding lectin is able to recognize most of glycans on cell surface of those microorganisms, which might help control the infection at the wound bed either by agglutinating those pathogens or activating the innate immune response. Through this perspective, a molecular modelling of Frutalin interaction with the TLR4/MD-2 receptor complex was provided through docking studies. Glycosylation on Asn8 and Asn96 residues of MD-2 molecule are pivotal for Frutalin's anchoring and activation of the complex TLR4/MD-2. In addition, TLR4 mediated the activation of neutrophils and it has a particular role to play in the regulation of neutrophil life span, and TLR4 signalling can regulate neutrophil survival [42]

We selected Frutalin for further study, mainly based on its strong stimulation of fibroblast migration in both scratch wound and Boyden two-chamber assays. However, our selection is endorsed by studies citing Frutalin's therapeutic potential in different areas, including anti-cancer activities in vitro [14], and by gastroprotection [16] or orofacial pain reduction [15] in preclinical studies. First, we added modest amounts $(50 \mu \mathrm{g} / \mathrm{mL})$ of Frutalin to fibroblast cultures and 
found significantly increased levels of p-ERK and MyD88 at both short $(0.5 \mathrm{~h})$ and long $(24 \mathrm{~h})$ times. The former is likely involved in fibroblast proliferation and the latter in TLR-4 receptor signaling when stimulated. TLR-4 stimulation may activate either MyD88-dependent or TRIF-dependent pathways [43]. As we found an increased level of MyD88 we assume that the fibroblast activation is mainly through MyD88 pathway. Additionally, we showed that the fibroblasts had been hyperstimulated (5-fold) to produce IL-6, a cytokine considered pyrogenic and associated with cell proliferation, as well as many innate immunity response pathways.

These diverse positive effects of Frutalin on fibroblasts, endorsed the next step of our work, namely to develop a lectin-carrier combination to steadily release Frutalin into microenvironments to promote desired healing actions. We chose galactomannan as the vehicle; it forms viscous hydrogel solutions at low concentrations, gives porous membrane scaffolds on freeze drying and is reported to provide stabilizing matrices for lectins $[44,45]$. However, unlike these earlier studies [44,45] we isolated the polysaccharide from Caesalpinia pulcherrima seeds. This species is readily cultivated in tropical semiarid regions, produces seeds 6 months after planting and, as we have described [36], is wellcharacterized and gave galactomannan yields of $\sim 25 \%$ from dried seed mass.

Hydrogels should exhibit basic features, such as swelling capacity, drug compatibility, safety, low toxicity, shelf stability and high purity; other requirements include biocompatibility, biodegradability, mechanical strength and multiple biofunctionalities. For tissue engineering, hydrogel biodegradability is essential as they invariably function as temporary extracellular matrix until replaced by new tissue, while bioactivity is essential for guiding cell behavior, such as proliferation, differentiation and matrix production [46]. Natural polymers are known to protect skin from harmful factors by such diverse hydrogel attributes and galactomannan, in particular, has cosmeceutical potential for its antioxidant and anti-aging actions [47].

Physico-chemical characterization of our Frutalin-galactomannan combinations showed that higher Frutalin levels increased galactomannan pseudoplasty, as viscosity was lost. The lectin interacts via $\mathrm{H}$ bonds with $\mathrm{OH}$ groups present in branches of the galactomannan chain; this can allow "sliding" of the chains, reducing galactomannan-galactomannan contact. It was evident by infrared spectroscopy as a band shift from $3350 \mathrm{~cm}^{-1}$ to $3595 \mathrm{~cm}^{-1}$ when Frutalin binds to galactomannan $\mathrm{OH}$ groups.

Oscillatory tests, performed with amplitude and frequency sweeps, can separate and quantify elastic and viscous parts of hydrogels by plotting graphs as a function of $G^{\prime}$ and G", respectively. Samples with G'> G'” values are classified as viscoelastic solid, while $G^{\prime \prime}>G^{\prime}$ indicates a viscoelastic liquid. Such analysis also allows calculation of sample Linear Viscoelastic Limit (LVE) i.e. the maximum deformation that the sample can undergo without permanent alteration of its structure. For our studies, the LVE value was held at $10 \%$ during frequency and temperature sweeps; this was the maximum deformation supported by our samples thus ensuring no structural changes occurred during the tests. Moreover, by subjecting samples to a varying oscillation frequency we could check stability in the short- and long-term (shelf life). Minor frequencies equate to long-term behaviour, while larger frequencies influence the shortterm. As we found $\mathrm{G}^{\prime \prime}>\mathrm{G}^{\prime}$ for all samples, they are viscoelastic liquids; despite the high viscosity of a $1.5 \%$ galactomannan solution, it does not have a gel-like or solid structure. Moreover, Frutalin additions did not alter this property, as for all concentrations examined the viscous portion (G”) exceeded the elastic portion (G'), consistent with liquid behaviour rather than that of a gel or solid.

Lyophilization of our hydrogels produced membrane scaffolds with a highly porous sponge-like structure containing macropores $(50-100 \mu \mathrm{m})$. The water vapor transmission rate (WVTR) is vital for the healing process. WVTR for normal skin, first degree burns, and granulating wounds are $(20 \pm 1) \times 10,(28 \pm 3) \times 10$, and $(51 \pm 2) \times 10^{2} \mathrm{~g} / \mathrm{m}^{2}$ day, respectively. So that, it is recommended that wound dressings should have WVTRs values in the range of (20-25) $\times 10^{2} \mathrm{~g} / \mathrm{m}^{2} \mathrm{day}$ [48]. Such water vapor permeability is pertinent to our work, since our membranes presented values ranging within $29.6 \pm 6.6$ $\mathrm{g} / \mathrm{m}^{2}$ day. Wound dressings must allow damaged skin to breathe as failure to restore oxygenation impairs healing [49]. In normal wound healing, reactive oxygen species (ROS) such as hydrogen peroxide $\left(\mathrm{H}_{2} \mathrm{O}_{2}\right)$ and superoxide $\left(\mathrm{O}_{2}^{-}\right)$act as cellular messengers to stimulate key processes, including cellular mobility, cytokine signaling and angiogenesis [50]. Such pathways are predicted to be stimulated by our Frutalin formulations, as in our previous pre-clinical studies we showed that antinociceptive and gastroprotective effects are mediated by nitrergic mechanisms [6,7].

Noteworthy too is the direct influence that the mannose:galactose ratio has on water vapor permeability. In galactamannan it is very low, resulting in many free mannose residues which in turn leads to dense packing of the chains and reduced diffusion of water vapor through the matrix [51]. However, we only observed a significant difference $(\mathrm{p}<0.05)$ between MF0 and MF01 $(\mathrm{P}<0.05)$, not for the membrane scaffolds with higher levels of Frutalin. Most likely this reflects that when Frutalin is freeze-dried in contact with galactomannan intractable spaces remain in the polymer, which are unaffected by further increases in Frutalin i.e. the extra lectin only fills spaces already generated by initial Frutalin-galactomannan interactions and, of course, the volume occupied by a lectin molecule is much smaller than the polysaccharide chairs.

In addition to the wound severity, multiple factors such as age, stress, sex hormones in aged individuals, diabetes, medications, obesity, alcohol consumption, smoking, and nutrition can cause impaired wound healing by affecting one or more phases of this complex process [50]. The excisional model in mice is an experimental model that may result in many extrapolations of the current healing process, emphasizing once again that tissue repair is a very dynamic event. Hydrogel liquid bandages, for example, are not recommended for stinging applications and/or open wound with significant extension area. Although those water-based formulations are less traumatic when applied to an open wound, the drying time in the wound bed can be long, and a polymer coating may be difficult to form because of flow of the 
formulation away of the injured area [52]. On the other hand, efforts have been made to develop membranes that mimic full-thickness skin wounds since those sort of dressings present suitable structure and properties for a better healing process, as they protect the wound from moisture loss and infection. Both hydrogels and membranes of our hybrid plant lectins/galactomannan formulations were tested in order to cover different ranges of topical applications. Hence, the hydrogels were applied daily, whereas the membrane scaffold was implanted once only on the day of surgery. Moreover, the membrane scaffolds carried 10 times more Frutalin than one $100 \mu \mathrm{L}$ hydrogel application, since this was sufficient to cover the entire injured area. Both treatments allowed the total recover of the wounded skin in 11 days. We suggest that $100 \mu \mathrm{g}$ of Frutalin/g of hydrogel or membrane as a helpful treatment in cutaneous wounds, especially in cases of infected wounds, burns and disease-related ulcers.

\section{Conclusions}

Of the four lectins investigated in the initial phase of this work, Frutalin was identified as the best candidate to take

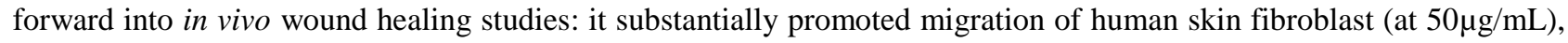
was non-cytotoxic and stimulated TLR4. We then assessed various combinations of Frutalin and galactomannan (isolated from C. pulcherrima) in hydrogels and, following their lyophilization, as membrane scaffolds for their efficacy in excision wound healing. Hydrogels were applied daily to the dorsal wounds of mice, while membrane scaffolds were implanted on the surgery day. Both formulations were effective with Frutalin at $100 \mu \mathrm{g} / \mathrm{g}$ galactomannan enhancing recovery from the dermal injuries after 11 days of treatment. We conclude that the breadfruit lectin, Frutalin, is a potential therapeutic biomolecule for wound healing and therapeutic approach to restore skin integrity, and perhaps other related skin diseases and injuries. Frutalin/galactomannan hybrids may represent an alternative to provide improved health care for wound, burn and surgical patients in addition to reducing the high cost of current health care treatment.

\section{Disclosure}

None

\section{Acknowledgements}

The authors would like to thank University of Fortaleza, Federal University of Ceará and University College London (UCL) for infrastructure. This work was supported by a grant from Conselho Nacional de Desenvolvimento Científico e Tecnológico (CNPq). Felipe Domingos de Sousa and Ayrles Fernanda Brandão da Silva were recipients of a PhD sandwich fellowship and post-doctoral research fellowship, respectively, at UCL [Grants: 201016/2015-0 and 205991/2014-9]. This work was also supported by Fundação Cearense de Apoio ao Desenvolvimento Científico e Tecnológico do Ceará (FUNCAP/SESA /MS/CNPq, Chamada 07/2013).

\section{Appendix A. Supplementary data}

Supplementary data associated with this article can be found in the online version.

\section{References}

[1] W.J. Peumans, E.J.M. Van Damme, Plant lectins: Versatile proteins with important perspectives in biotechnology, Biotechnol. Genet. Eng. Rev. 15 (1998) 199-228. doi:10.1080/02648725.1998.10647956.

[2] J. Arnaud, A. Audfray, A. Imberty, Binding sugars: from natural lectins to synthetic receptors and engineered neolectins., Chem. Soc. Rev. 42 (2013) 4798-4813. doi:10.1039/c2cs35435g.

[3] S. Fanayan, M. Hincapie, W.S. Hancock, Using lectins to harvest the plasma/serum glycoproteome, Electrophoresis. 33 (2012) 1746-1754. doi:10.1002/elps.201100567.

[4] C. Oliveira, A. Nicolau, J.A. Teixeira, L. Domingues, Cytotoxic effects of native and recombinant frutalin, a plant galactose-binding lectin, on Hela cervical cancer cells, J. Biomed. Biotechnol. 2011 (2011). doi:10.1155/2011/568932.

[5] A.C. Brando-Lima, R.F. Saldanha-Gama, C.R. Pereira, C.G. Villela, A.L.F. Sampaio, A.C.O. MonteiroMoreira, M.D.G.M.O. Henriques, R.A. Moreira, C. Barja-Fidalgo, Involvement of phosphatidylinositol-3 kinase-Akt and nuclear factor kappa-B pathways in the effect of frutalin on human lymphocyte, Int. Immunopharmacol. 6 (2006) 465-472. doi:10.1016/j.intimp.2005.09.008. 
Neto, R.D.A. Moreira, A.C.D.O. Monteiro-Moreira, A.R. Campos, Frutalin reduces acute and neuropathic nociceptive behaviours in rodent models of orofacial pain, Chem. Biol. Interact. 256 (2016) 9-15. doi:10.1016/j.cbi.2016.06.016.

[7] A.P.D.V. Abdon, G.C. De Souza, L.N.C. De Souza, R.P. Vasconcelos, C.A. Castro, M.M. Guedes, R.C.P. Lima-Júnior, R.D.A. Moreira, A.C.D.O. Monteiro-Moreira, A. Rolim-Campos, Gastroprotective potential of frutalin, a D-galactose binding lectin, against ethanol-induced gastric lesions, Fitoterapia. 83 (2012) 604-608. doi:10.1016/j.fitote.2012.01.005.

[8] J.R.C. Araújo, J. de M.A. de M. Júnior, M. de B.M.V. Damasceno, S.A.A.R. Santos, A.E. Vieira-Neto, M.D.P. Lobo, A.R. Campos, R. de A. Moreira, A.C. de O. Monteiro-Moreira, Neuropharmacological characterization of frutalin in mice: Evidence of an antidepressant-like effect mediated by the NMDA receptor/NO/cGMP pathway, Int. J. Biol. Macromol. 112 (2018) 548-554. doi:10.1016/j.ijbiomac.2018.01.180.

[9] R.A. Moreira, A.C.O. Monteiro, A.C.G. Horta, J.T.A. Oliveira, B.S. Cavada, Isolation and characterization of Dioclea altissima var. megacarpa seed lectin, Phytochemistry. 46 (1997) 139-144. doi:10.1016/S00319422(97)00262-8.

[10] S.K. Natchiar, O. Srinivas, N. Mitra, A. Surolia, N. Jayaraman, M. Vijayan, Structural studies on peanut lectin complexed with disaccharides involving different linkages: Further insights into the structure and interactions of the lectin, Acta Crystallogr. Sect. D Biol. Crystallogr. 62 (2006) 1413-1421. doi:10.1107/S0907444906035712.

[11] L. Chaires-Martínez, J. A. Salazar-Montoya, E.G. Ramos-Ramírez, Physicochemical and functional characterization of the galactomannan obtained from mesquite seeds (Prosopis pallida), Eur. Food Res. Technol. 227 (2008) 1669-1676. doi:10.1007/s00217-008-0892-0.

[12] K.S. Mikkonen, H. Rita, H. Hele, R.A. Talja, L. Hyvo, Effect of Polysaccharide Structure on Mechanical and Thermal Properties of Galactomannan-Based Films, Biomacromolecules. 8 (2007) 3198-3205. doi:10.1021/bm700538c.

[13] M. Srivastava, V.P. Kapoor, Seed Galactomannans : An Overview, Chem. Biodivers. 2 (2005) $295-317$. doi:10.1002/cbdv.200590013.

[14] C.A. Finch, Book Review: Hydrocolloid applications - gum technology in the food and other industries, Blackie Academic \& Professional, London, 1998. doi:10.1002/(SICI)1097-0126(199804)45:4<428::AIDPI962>3.0.CO;2-N.

[15] C. Cevoli, F. Balestra, L. Ragni, A. Fabbri, Rheological characterisation of selected food hydrocolloids by traditional and simplified techniques, Food Hydrocoll. 33 (2013) 142-150. doi:10.1016/j.foodhyd.2013.02.022.

[16] V.D. Prajapati, G.K. Jani, N.G. Moradiya, N.P. Randeria, B.J. Nagar, N.N. Naikwadi, B.C. Variya, Galactomannan: a versatile biodegradable seed polysaccharide., Int. J. Biol. Macromol. 60 (2013) 83-92. doi:10.1016/j.ijbiomac.2013.05.017.

[17] M.A. Cerqueira, A.C. Pinheiro, B.W.S. Souza, A.M.P. Lima, C. Ribeiro, C. Miranda, J.A. Teixeira, R.A. Moreira, M.A. Coimbra, M.P. Gonçalves, A.A. Vicente, Extraction, purification and characterization of galactomannans from non-traditional sources, Carbohydr. Polym. 75 (2009) 408-414. doi:10.1016/j.carbpol.2008.07.036.

[18] C.T. Andrade, E.G. Azero, L. Luciano, M.P. Gonc, Solution properties of the galactomannans extracted from the seeds of Caesalpinia pulcherrima and Cassia javanica : comparison with locust bean gum, Int. J. Biol. Macromol. 26 (1999) 181-185. doi:https://doi.org/10.1016/S0141-8130(99)00075-6.

[19] A. Grenha, M. Dionísio, Locust bean gum: Exploring its potential for biopharmaceutical applications, J. Pharm. Bioallied Sci. 4 (2012) 175. doi:10.4103/0975-7406.99013.

[20] N.M. Siqueira, B. Paiva, M. Camassola, E.Q. Rosenthal-Kim, K.C. Garcia, F.P. Dos Santos, R.M.D. Soares, Gelatin and galactomannan-based scaffolds: Characterization and potential for tissue engineering applications, Carbohydr. Polym. 133 (2015) 8-18. doi:10.1016/j.carbpol.2015.06.039.

[21] L. Bedian, A.M.V. Rodríguez, G.H. Vargas, R. Parra-Saldivar, H.M.N. Iqbal, Bio-based materials with novel characteristics for tissue engineering applications - A review, Int. J. Biol. Macromol. 98 (2017) 837-846. doi:10.1016/j.ijbiomac.2017.02.048.

[22] D. Harper, A. Young, C.E. McNaught, The physiology of wound healing, Surg. (United Kingdom). 32 (2014) 445-450. doi:10.1016/j.mpsur.2014.06.010.

[23] R.A. Moreira, J.C. Perrone, Purification and partial characterization of a lectin from Phaseolus vulgaris., Plant Physiol. 59 (1977) 783-7. doi:10.1104/pp.59.5.783.

[24] F.D. de Sousa, B.B. da Silva, G.P. Furtado, I. de S. Carneiro, M.D.P. Lobo, Y. Guan, J. Guo, A.R. Coker, M.R. 
Lourenzoni, M.I.F. Guedes, J.S. Owen, D.J. Abraham, A.C. de O. Monteiro-Moreira, R. de A. Moreira, Frutapin, a lectin from Artocarpus incisa (breadfruit): cloning, expression and molecular insights, Biosci. Rep. 37 (2017) BSR20170969. doi:10.1042/BSR20170969.

[25] AOAC, Official Methods of Analysis of AOAC International, Assoc. Off. Anal. Chem. Int. (2000) Method ce 2-66. doi:10.3109/15563657608988149.

[26] NCCLS, NCCLS document M7-A10, in: Methods Dilution Antimicrob. Susceptibility Tests Bact. That Grow Aerob. Approv. Stand., 2015: pp. M7-A10. http://shop.clsi.org/microbiology-documents/M07-M100-PK.html.

[27] M. Fronza, B. Heinzmann, M. Hamburger, S. Laufer, I. Merfort, Determination of the wound healing effect of Calendula extracts using the scratch assay with 3T3 fibroblasts, J. Ethnopharmacol. 126 (2009) 463-467. doi:10.1016/j.jep.2009.09.014.

[28] G.C.P. Van Zundert, J.P.G.L.M. Rodrigues, M. Trellet, C. Schmitz, P.L. Kastritis, E. Karaca, A.S.J. Melquiond, M. Van Dijk, S.J. De Vries, A.M.J.J. Bonvin, The HADDOCK2.2 Web Server: User-Friendly Integrative Modeling of Biomolecular Complexes, J. Mol. Biol. 428 (2016) 720-725. doi:10.1016/j.jmb.2015.09.014.

[29] T.A. Wassenaar, M. van Dijk, N. Loureiro-Ferreira, G. van der Schot, S.J. de Vries, C. Schmitz, J. van der Zwan, R. Boelens, A. Giachetti, L. Ferella, A. Rosato, I. Bertini, T. Herrmann, H.R.A. Jonker, A. Bagaria, V. Jaravine, P. Güntert, H. Schwalbe, W.F. Vranken, J.F. Doreleijers, G. Vriend, G.W. Vuister, D. Franke, A. Kikhney, D.I. Svergun, R.H. Fogh, J. Ionides, E.D. Laue, C. Spronk, S. Jurkša, M. Verlato, S. Badoer, S. Dal Pra, M. Mazzucato, E. Frizziero, A.M.J.J. Bonvin, WeNMR: Structural Biology on the Grid, J. Grid Comput. 10 (2012) 743-767. doi:10.1007/s10723-012-9246-z.

[30] Y.C. Lu, W.C. Yeh, P.S. Ohashi, LPS/TLR4 signal transduction pathway, Cytokine. 42 (2008) 145-151. doi:10.1016/j.cyto.2008.01.006.

[31] Council of Europe, The European Pharmacopoeia 8th (Ph.Eur.), 2014.

[32] ASTM, ASTM E96 Standard Test Methods for Water Vapor Transmission of Materials, ASTM Stand. 14 (2002) 1-10. doi:10.1520/E0096.

[33] I.S.T. De Figueiredo, M.V. Ramos, N.M.P.S. Ricardo, M.L.D.C. Gonzaga, R.S.P. Pinheiro, N.M.N. De Alencar, Efficacy of a membrane composed of polyvinyl alcohol as a vehicle for releasing of wound healing proteins belonging to latex of Calotropis procera, Process Biochem. 49 (2014) 512-519. doi:10.1016/j.procbio.2013.12.015.

[34] F.C. John, K. Tabbasum, C.P. Rao, Chemico-biological aspects of plant lectins with a preference to legume lectins, 1st ed., Copyright ( 2013 Elsevier B.V. All rights reserved., 2013. doi:10.1016/B978-0-444-59603$1.00010-2$.

[35] A.C.O. Monteiro-Moreira, H. D’Muniz Pereira, A.E. Vieira-Neto, F.B.M.B. Moreno, M.D.P. Lobo, F.D. Sousa, R.A. Moreira, Crystallization and preliminary X-ray diffraction studies of frutalin, an $\alpha$-D-galactose-specific lectin from Artocarpus incisa seeds, Acta Crystallogr. Sect. F Struct. Biol. Commun. F71 (2015) 1282-1285. doi:10.1107/S2053230X15015186.

[36] M.B. Trindade, J.L.S. Lopes, A. Soares-Costa, A.C. Monteiro-Moreira, R.A. Moreira, M.L. V. Oliva, L.M. Beltramini, Structural characterization of novel chitin-binding lectins from the genus Artocarpus and their antifungal activity, Biochim. Biophys. Acta - Proteins Proteomics. 1764 (2006) 146-152. doi:10.1016/j.bbapap.2005.09.011.

[37] H. Singh, S.P. Sarathi, Insight of Lectins- A review, Int. J. Sci. Eng. Res. 3 (2012) 1-9.

[38] C. Oliveira, J.A. Teixeira, L. Domingues, Recombinant production of plant lectins in microbial systems for biomedical application - the frutalin case study., Front. Plant Sci. 5 (2014) 390. doi:10.3389/fpls.2014.00390.

[39] P. Huebener, R.F. Schwabe, Regulation of wound healing and organ fibrosis by toll-like receptors, Biochim. Biophys. Acta - Mol. Basis Dis. 1832 (2013) 1005-1017. doi:10.1016/j.bbadis.2012.11.017.

[40] C. Vaure, Y. Liu, A comparative review of toll-like receptor 4 expression and functionality in different animal species, Front. Immunol. 5 (2014) 1-15. doi:10.3389/fimmu.2014.00316.

[41] M.J. Portou, D. Baker, D. Abraham, J. Tsui, The innate immune system, toll-like receptors and dermal wound healing: A review, Vascul. Pharmacol. 71 (2015) 31-36. doi:10.1016/j.vph.2015.02.007.

[42] I. Sabroe, L.R. Prince, E.C. Jones, M.J. Horsburgh, S.J. Foster, S.N. Vogel, S.K. Dower, M.K.B. Whyte, Selective Roles for Toll-Like Receptor (TLR)2 and TLR4 in the Regulation of Neutrophil Activation and Life Span, J. Immunol. 170 (2003) 5268-5275. doi:10.4049/jimmunol.170.10.5268.

[43] V. Premkumar, M. Dey, R. Dorn, I. Raskin, MyD88-dependent and independent pathways of toll-like receptors 
are engaged in biological activity of triptolide in ligand-stimulated macrophages, BMC Chem. Biol. 10 (2010). doi:10.1186/1472-6769-10-3.

[44] P.B.S. Albuquerque, C.S. Silva, P.A.G. Soares, W. Barros, M.T.S. Correia, L.C.B.B. Coelho, J.A. Teixeira, M.G. Carneiro-da-Cunha, Investigating a galactomannan gel obtained from Cassia grandis seeds as immobilizing matrix for Cramoll lectin, Int. J. Biol. Macromol. 86 (2016) 454-461. doi:10.1016/j.ijbiomac.2016.01.107.

[45] P.A.G. Soares, J.R.P. C De Seixas, P.B.S. Albuquerque, G.R.C. Santos, P.A.S. Mourão, W. Barros, M.T.S. Correia, M.G. Carneiro-Da-Cunha, Development and characterization of a new hydrogel based on galactomannan and k-carrageenan, Carbohydr. Polym. 134 (2015) 673-679. doi:10.1016/j.carbpol.2015.08.042.

[46] R. Jin, P.J. Dijkstra, Hydrogels for Tissue Engineering Applications, in: R.M. Ottenbrite, K. Park, T. Okano (Eds.), Biomed. Appl. Hydrogels Handb., Springer International Publishing, New York, 2010: pp. 215-225. doi:10.1007/978-1-4419-5919-5.

[47] M. Yanti, A. Soegianto, Cosmeceutical effects of galactomannan fraction from Arenga pinnata fruits in vitro, Pharmacognosy Res. 9 (2017) 39-45. doi:10.4103/0974-8490.199773.

[48] P.I. Morgado, A. Aguiar-Ricardo, I.J. Correia, Asymmetric membranes as ideal wound dressings: An overview on production methods, structure, properties and performance relationship, J. Memb. Sci. 490 (2015) 139-151. doi:10.1016/j.memsci.2015.04.064.

[49] C.K. Sen, S. Roy, Oxygenation state as a driver of myofibroblast differentiation and wound contraction: Hypoxia impairs wound closure, J. Invest. Dermatol. 130 (2010) 2701-2703. doi:10.1038/jid.2010.316.

[50] S. Guo, L.A. Dipietro, Factors Affecting Wound Healing, J. Dent. Res. 89 (2010) 219-223. doi:10.1177/0022034509359125.

[51] V.R.F. Dos Santos, B.W.S. Souza, J.A. Teixeira, A.A. Vicente, M.A. Cerqueira, Relationship between galactomannan structure and physicochemical properties of films produced thereof, J. Food Sci. Technol. 52 (2015) 8292-8299. doi:10.1007/s13197-015-1961-6.

[52] J.C. Salamone, A.B. Salamone, K. Swindle-Reilly, K.X.-C. Leung, R.E. McMahon, Grand challenge in Biomaterials-wound healing, Regen. Biomater. (2016) 127-128. doi:10.1093/rb/rbw015.

\section{Figure Legends}


Fig. 1. Agglutination of pathogenic microorganisms induced by Frutalin, Jacalin, PNA or DAL. The control was PBS.

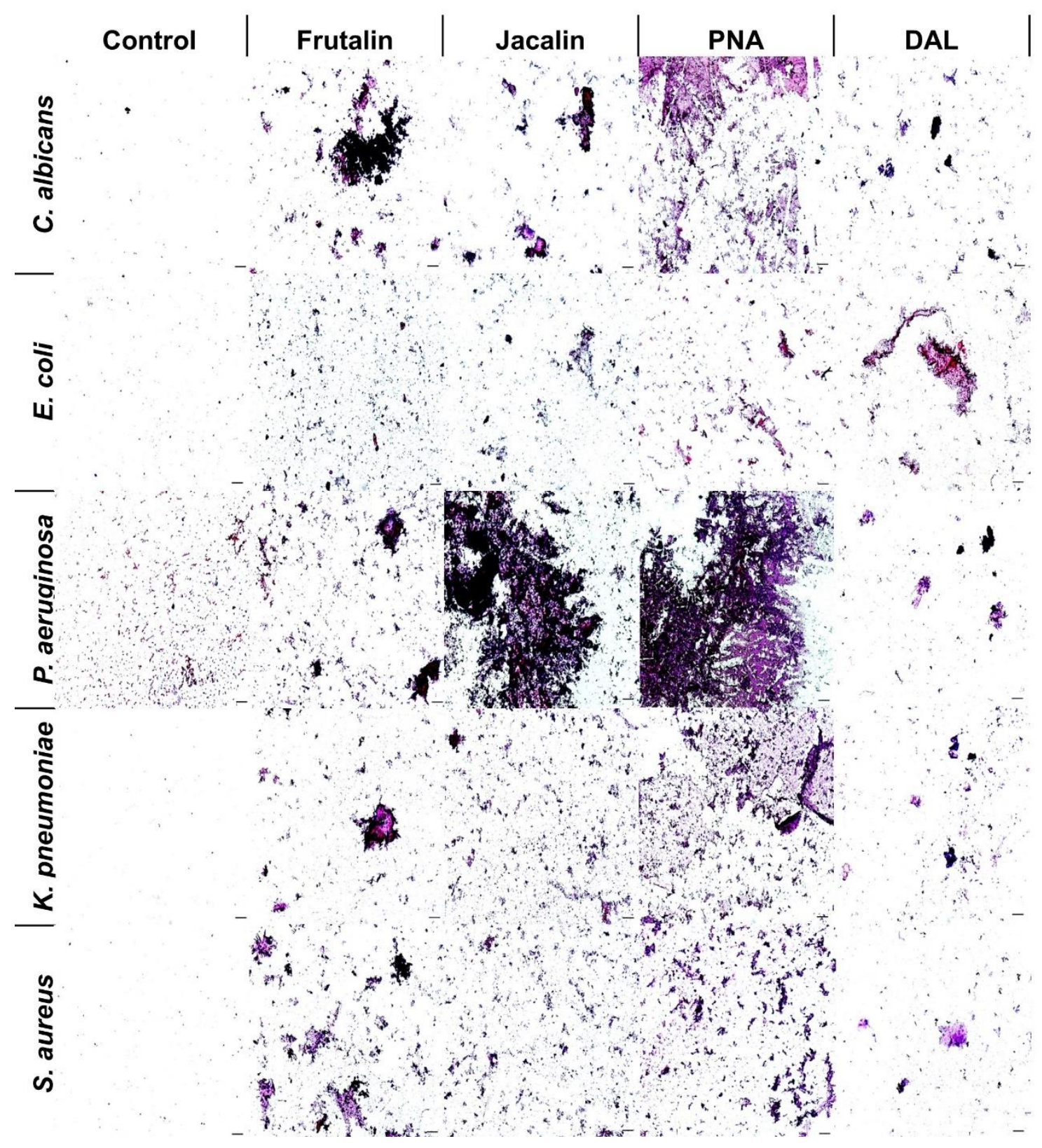


Fig. 2. Lectins activate TLR4 signalling. HEK-Blue hTLR4 cells were used in a reporter assay to determine whether Frutalin, Jacalin, DAL and PNA $(50 \mu \mathrm{g} / \mathrm{mL})$ were TLR4 agonists. LPS $(100 \mathrm{ng} / \mathrm{mL})$ was used as a positive control.

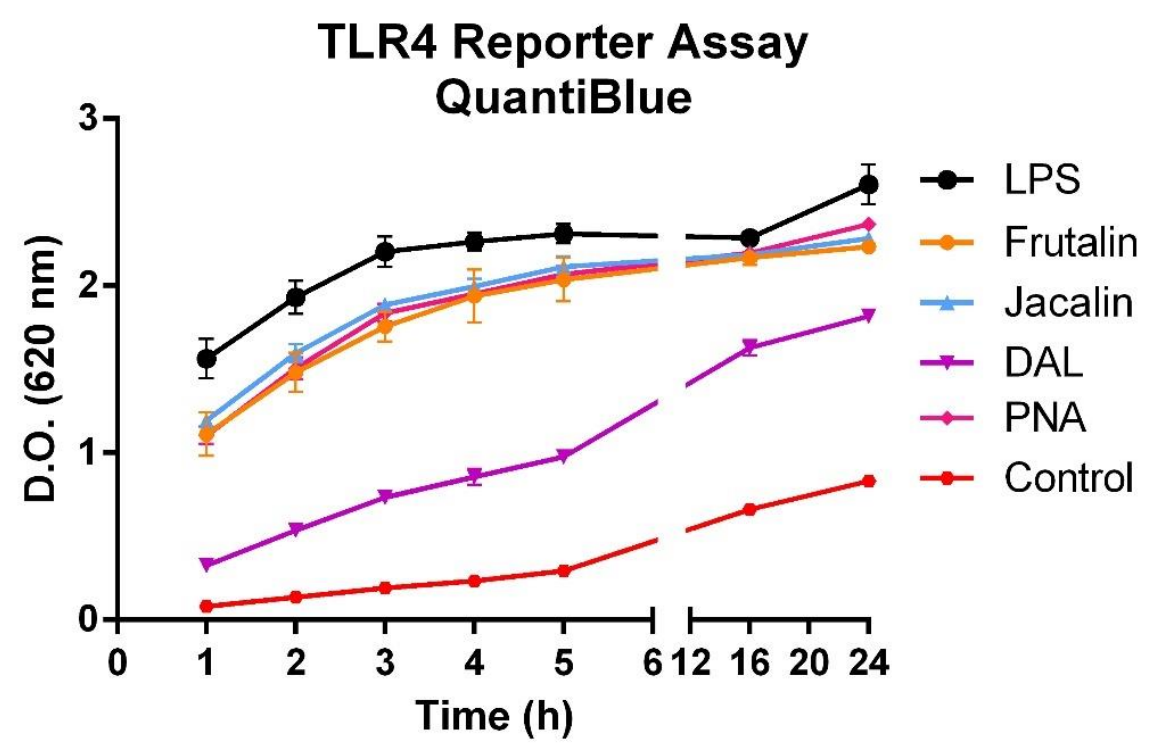


Fig. 3. Modelling of TLR4-MD-2/Frutalin interactions. Frutalin (blue) is shown docked with a TLR4/MD2-complex in an apposite interaction. TLR4 (red) is attached to a mock cellular membrane (gray lines), while the Asn8 and Asn96 residues of MD-2 (yellow) are shown glycosylated (magenta).

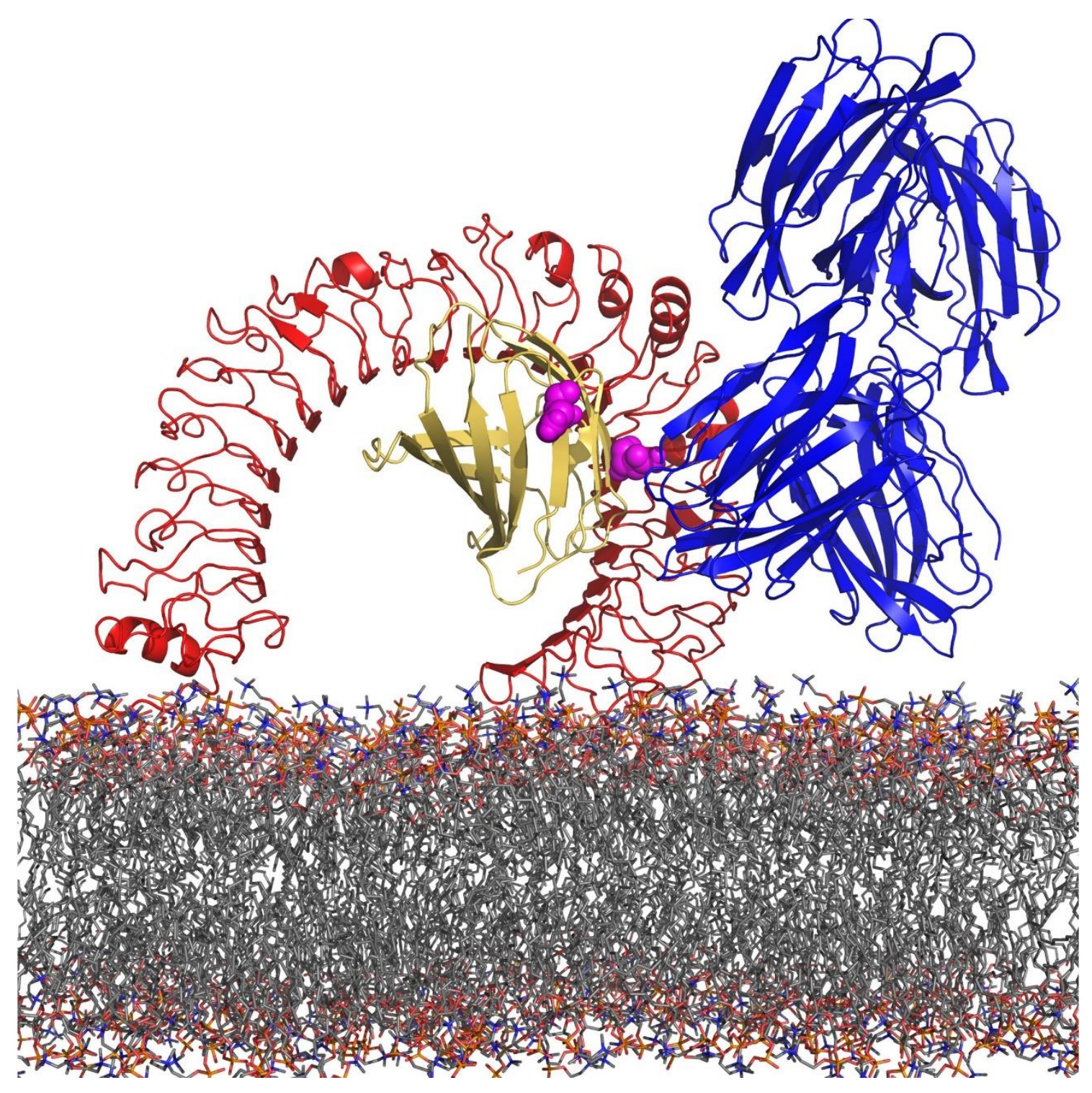


Fig.4. Frutalin stimulates fibroblast migration. (A) Scratch wound assay using normal human skin fibroblasts (NHSF) incubated with Frutalin $(50 \mu \mathrm{g} / \mathrm{mL})$. (B) NHSF migration using Boyden chambers. A: medium only. B: Frutalin $(50 \mu \mathrm{g} / \mathrm{mL})$ in lower chamber only. C: Frutalin $(50 \mu \mathrm{g} / \mathrm{mL})$ in both lower and upper chambers. Scale bar $=100 \mu \mathrm{m} . \quad(* * * * p<0.0001 ; * * * p<0.001)$

A

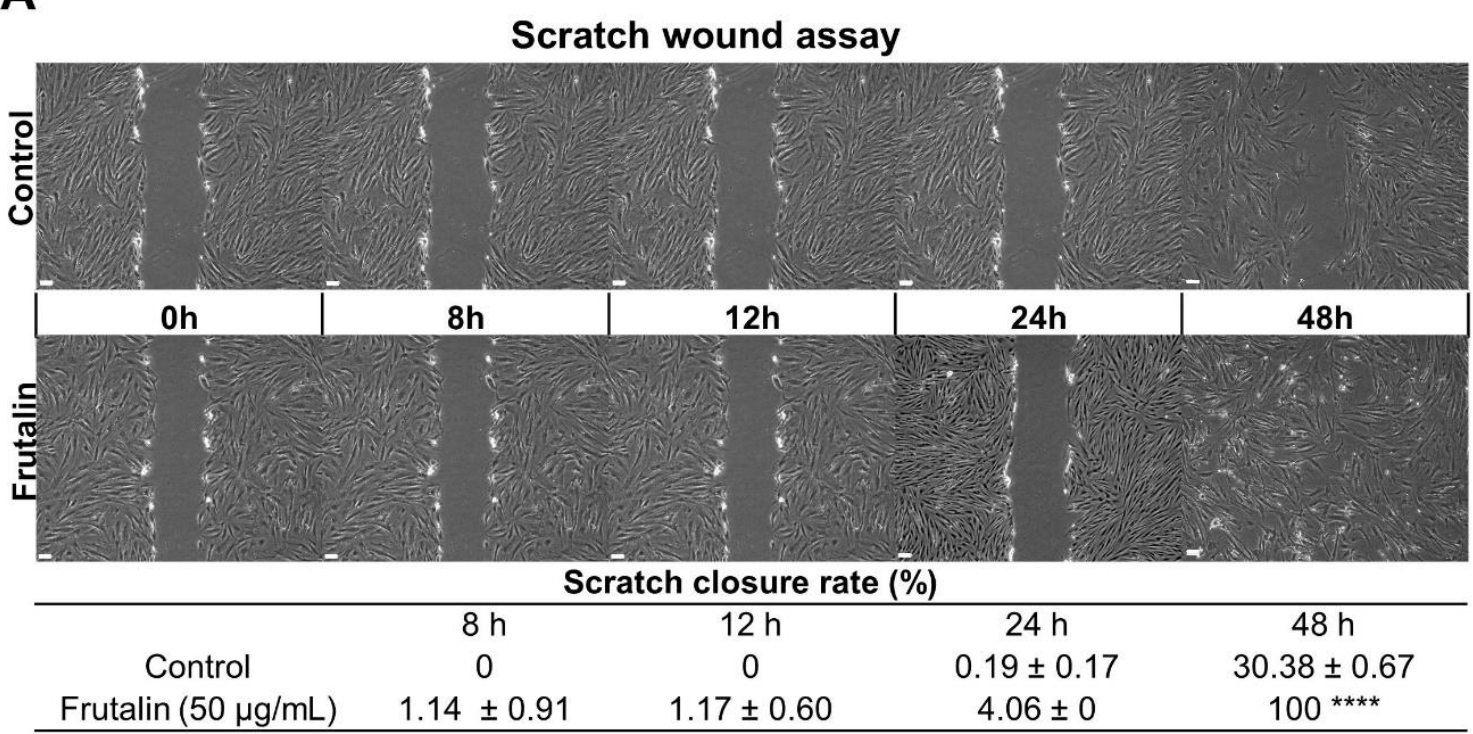

B

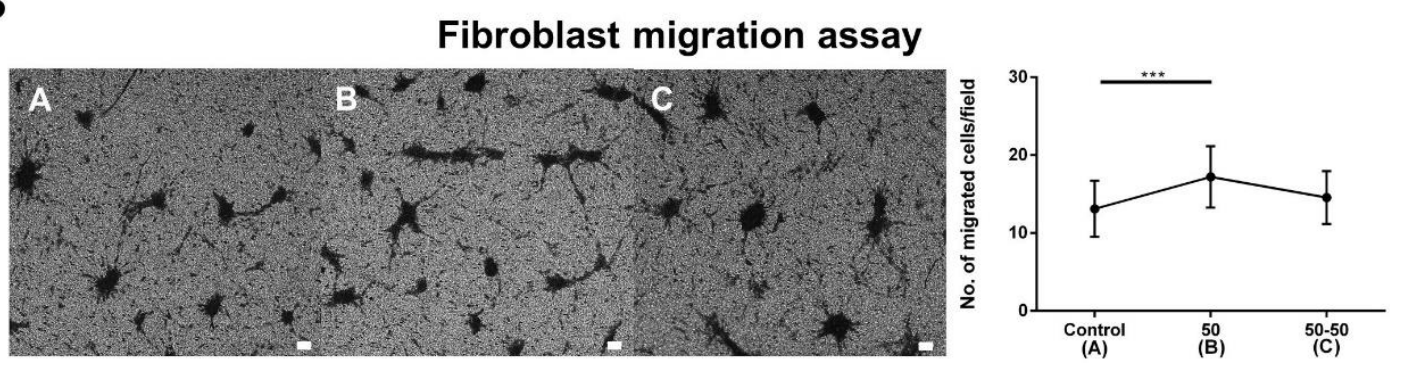


Fig. 5. Effect of Frutalin $(50 \mu \mathrm{g} / \mathrm{mL})$ on NHSF physiology over time. $(* \mathrm{p}<0.05 ; * * \mathrm{p}<0.01)$
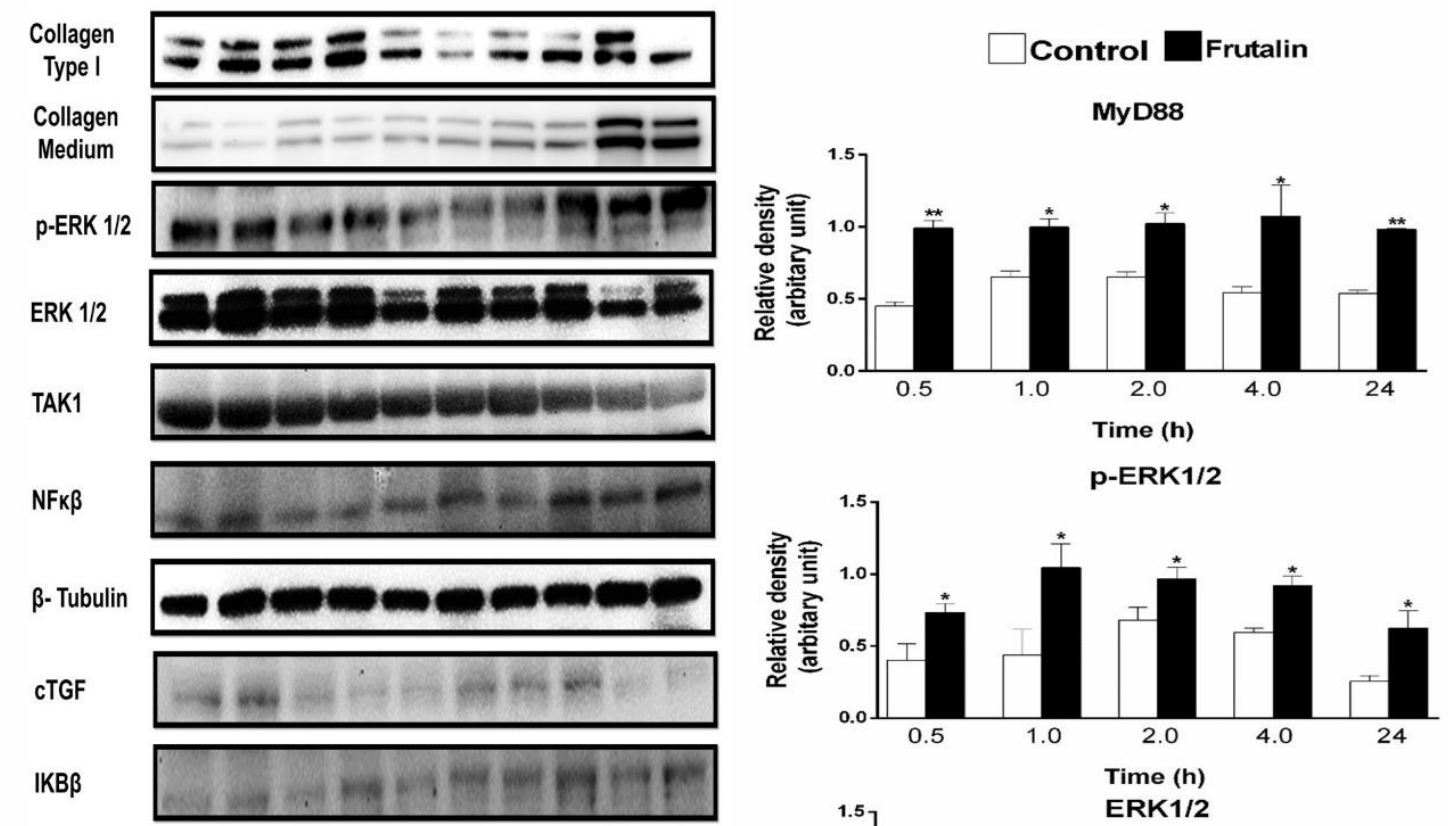

MyD88

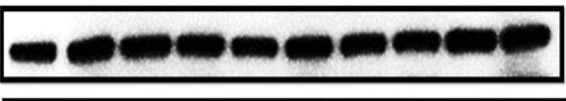

cTGF
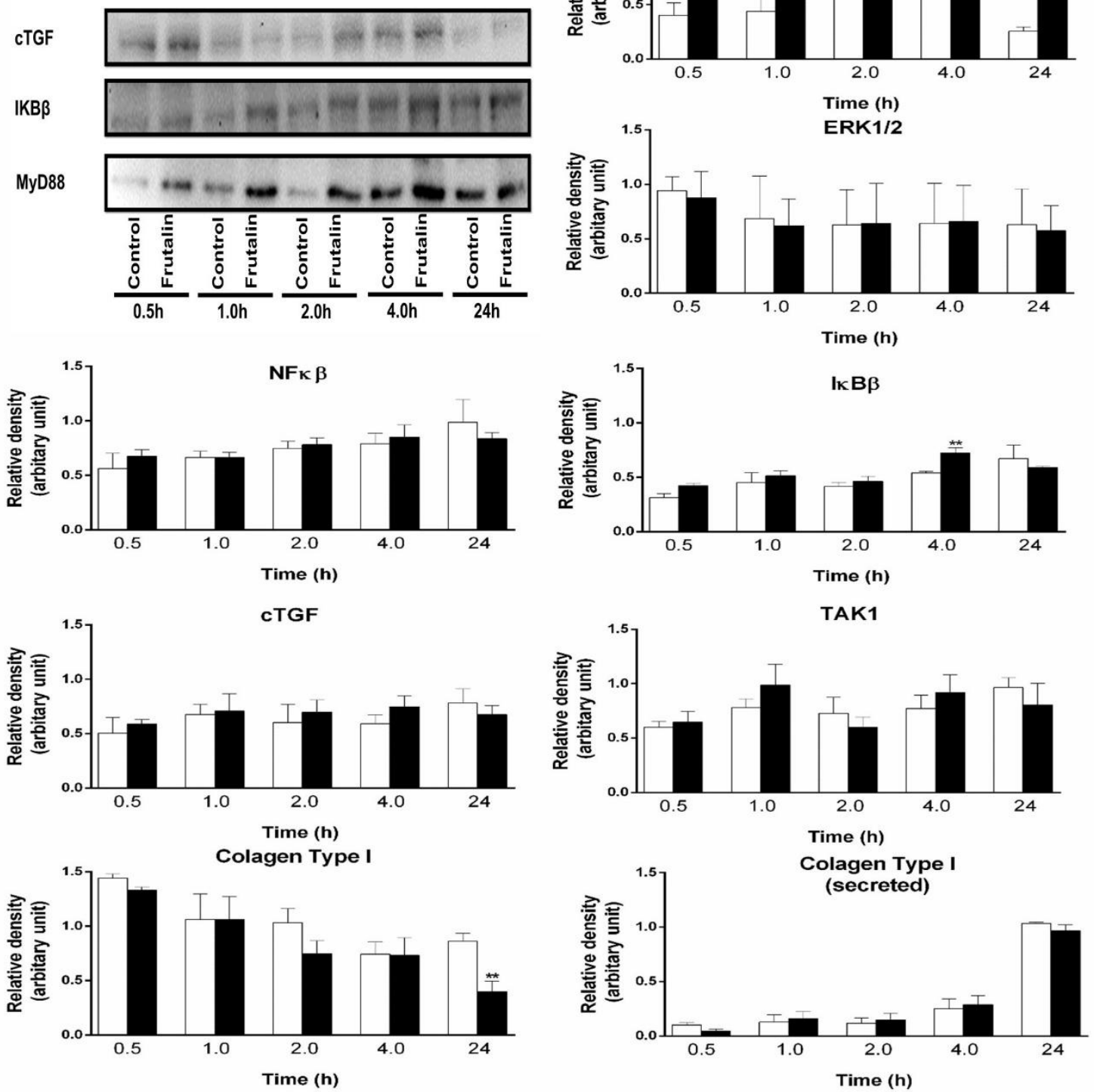
Fig. 6.

(A) Flow curves of Frutalin/galactomannan-based hydrogels. These were: F0, pure galactomannan hydrogel at $1.5 \%$, which was used to prepare the Frutalin formulations, F01, F05 and F10 containing 0.1, 0.5 and 1.0 mg Frutalin/g galactomannan hydrogel, respectively. (B) Rheological parameters by the Power Law model, indicating that Frutalin reduces the pseudoplasty of galactomannan hydrogels. (C) Stress-strain experiments. The storage (G') and loss (G') moduli are displayed as a function of applied shear stress for the galactomannan-based hydrogel (F0) and hydrogels containing Frutalin (F01, F05 and F10); all data were obtained at the linear viscoelastic region (LVR). (C) G' and G" moduli as a function of an oscillatory stress frequency and (D)temperature.
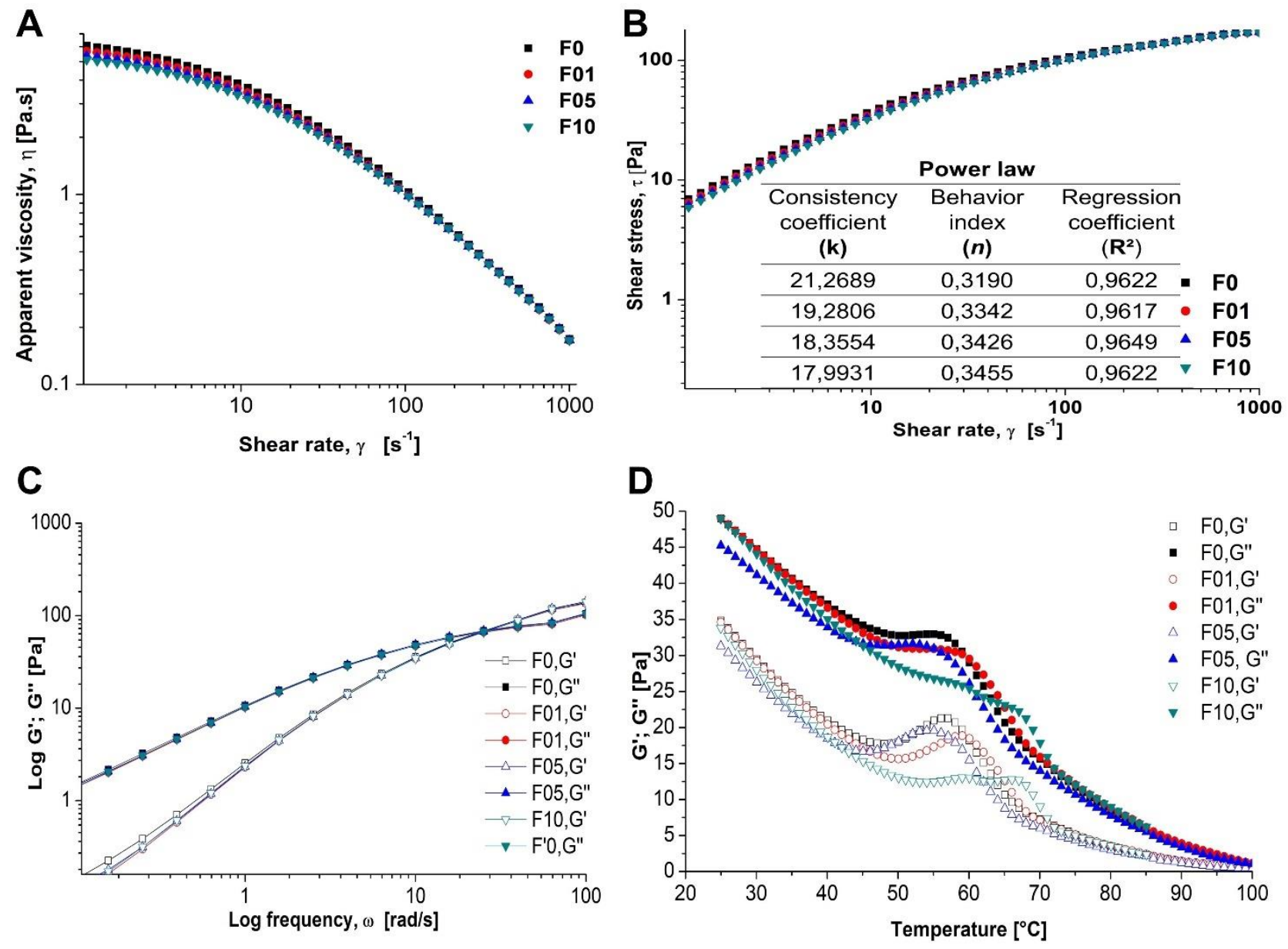
Fig.7.

FTIR and SEM of Frutalin/galactomannan-based membrane scaffolds. MF0, pure galactomannan-based scaffold membrane hydrogel at $1.5 \%$, which was used to prepare the Frutalin formulations, MF01, MF05 and MF10 containing 0.1, 0.5 and $1.0 \mathrm{mg}$ Frutalin/g galactomannan hydrogel, respectively. (A) FTIR scans and (B) SEM images (x2000 magnification, scale bar $=20 \mu \mathrm{m}$ ) of each porous membrane scaffold.
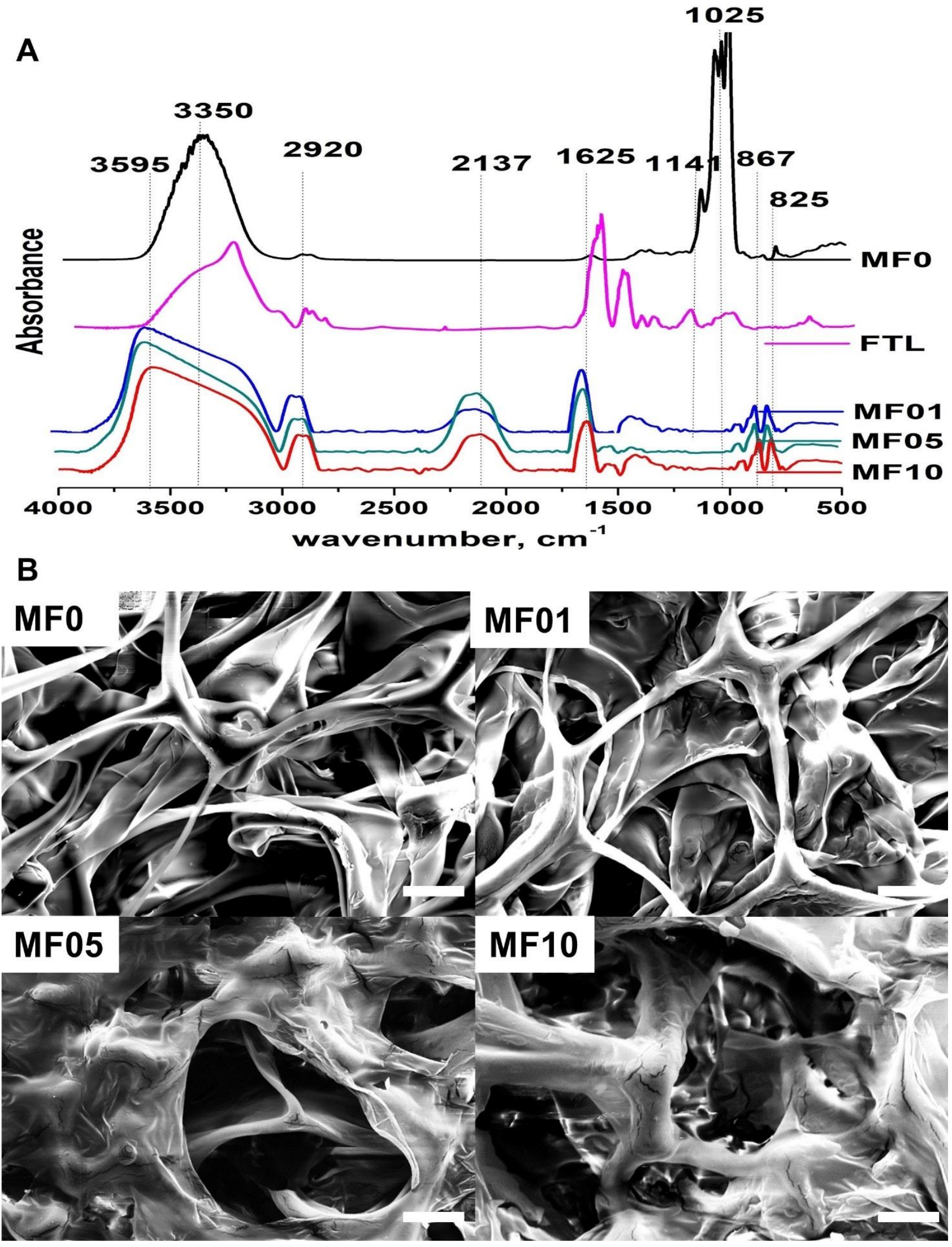


\section{Fig.8.}

Histological analysis of dermal wound healing with hydrogels. Light microphotographs of haematoxylin and eosin stained skin sections after 3, 7, 11 and 14 days of treatment with saline solution (negative control) and hydrogel-treated animals (F0, F01, F05 and F10). C: crust; gt: granulation tissue; ep: epithelization; v: vascularization; fb: fibroblast; and k: keratin. $($ scale bar $=100 \mu \mathrm{m})$.

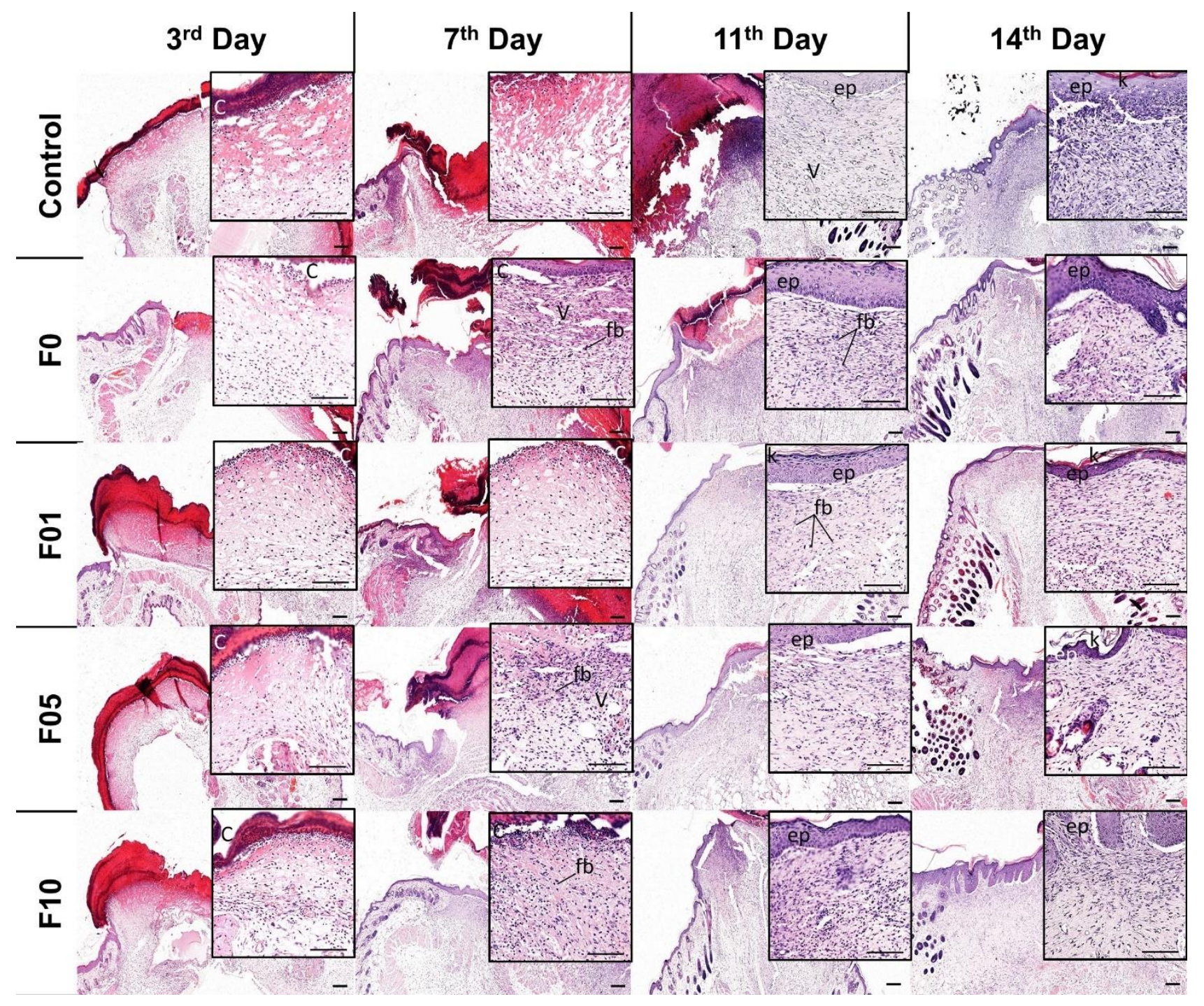


Fig.9.

Histological analysis of dermal wound healing with membrane scaffolds. Light microphotographs of haematoxylin and eosin stained skin sections after 3, 7,11 and 14 days of treatment with saline solution (negative control) and membrane-treated animals (MF0, MF01, MF05 and MF10). C: crust; gt: granulation tissue; ep: epithelization; v: vascularization; fb: fibroblast; and k: keratin. (scale bar $=100 \mu \mathrm{m}$ ).

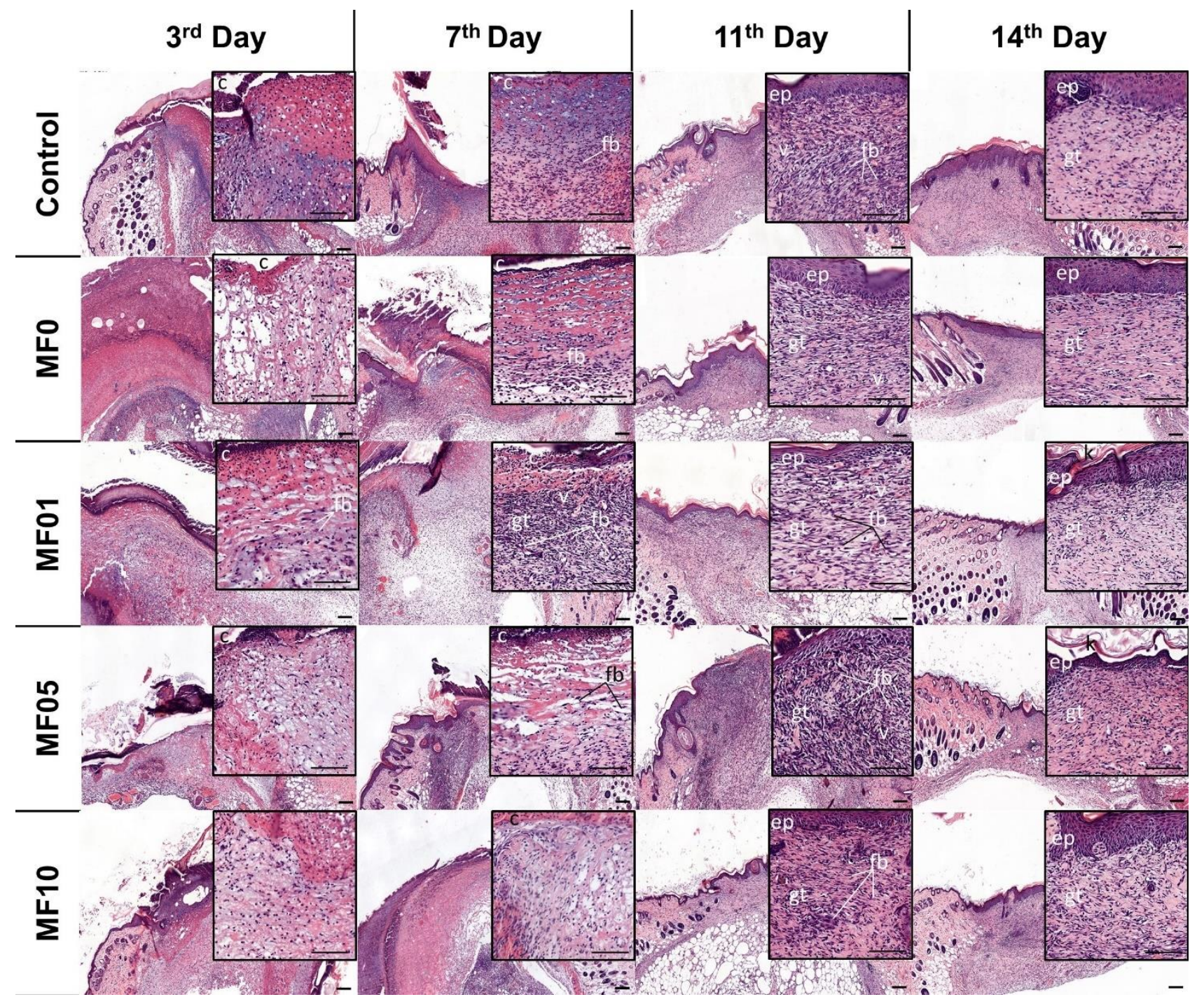




\section{Supplementary Figures}

Supplementary Fig. S1: (A) Electrophoresis showing the high purity of the extracted and purified seed lectins, Frutalin, Jacalin, PNA and DAL.

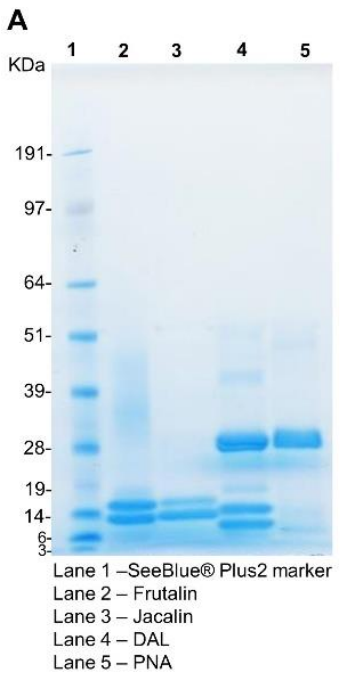


Supplementary Fig. S2. Cell viability assay following incubation of human skin fibroblasts with the four extracted seed lectins, Frutalin, Jacalin, DAL and PNA.
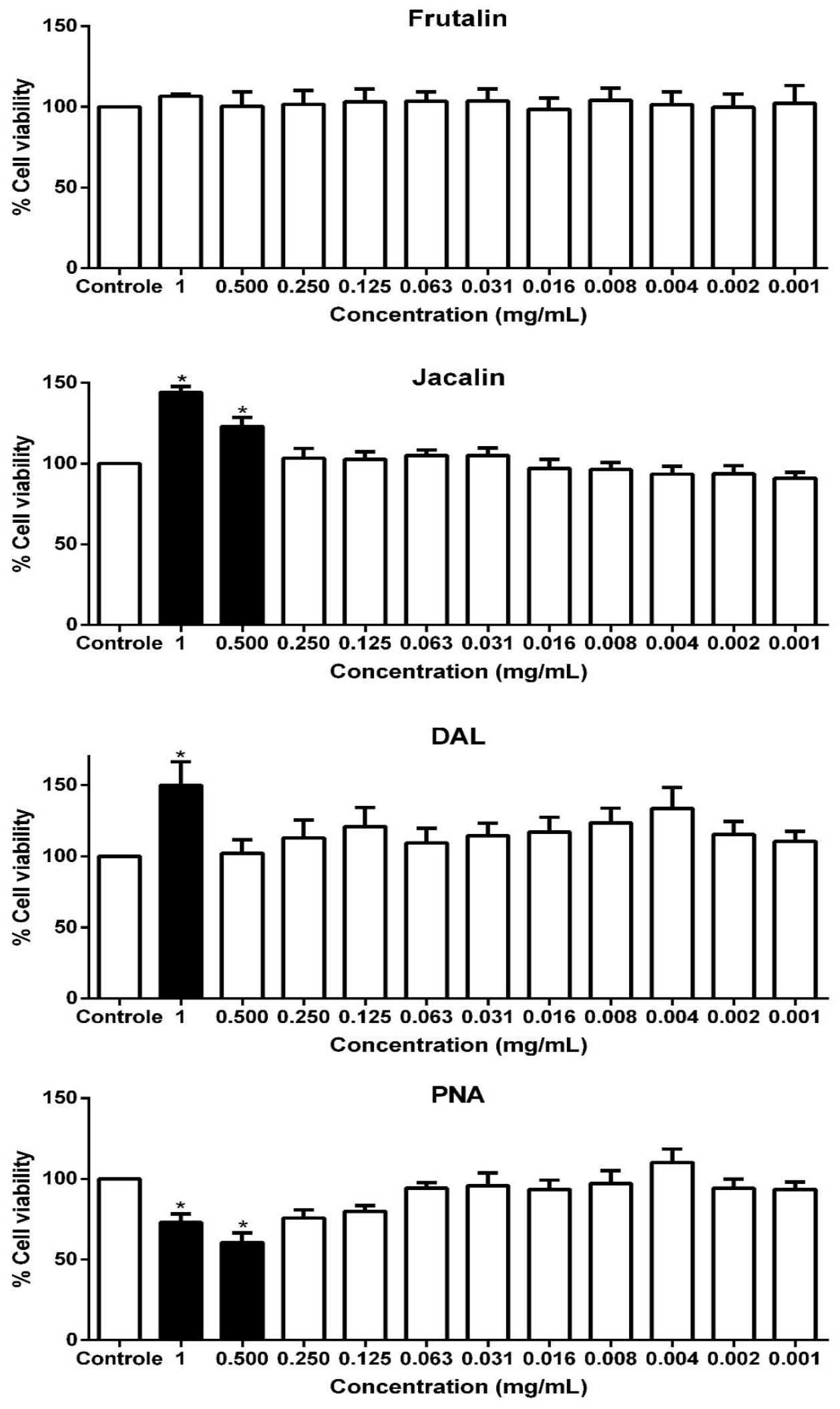
Supplementary Fig. S3. Increased IL-6 secretion by human skin fibroblast following $24 \mathrm{~h}$ incubation with Frutalin $(50 \mu \mathrm{g} / \mathrm{mL})$. Control cells received culture medium alone and the two compared by Student's $\mathrm{t}$ test $(* * * * \mathrm{p}<0.0001)$

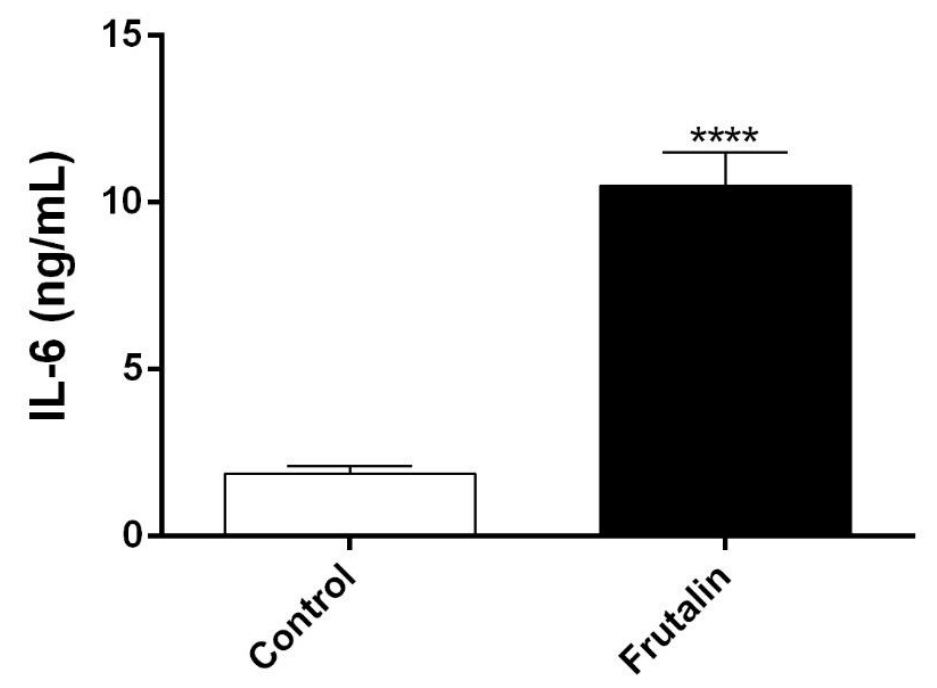

Supplementary Fig. S4. Water Vapor Permeability (WVP) of Frutalin-galactomannan membrane scaffolds. The samples tested were MF0 (galactomannan hydrogel alone; control) plus MF01, MF05 and MF10, containing $0.1,0.5$ and $1.0 \mathrm{mg}$ Frutalin/g galactomannan hydrogel, respectively. Statistical comparisons were made using ANOVA and Tukey's multiple comparisons test $\left({ }^{*} \mathrm{p}<0.05\right)$.

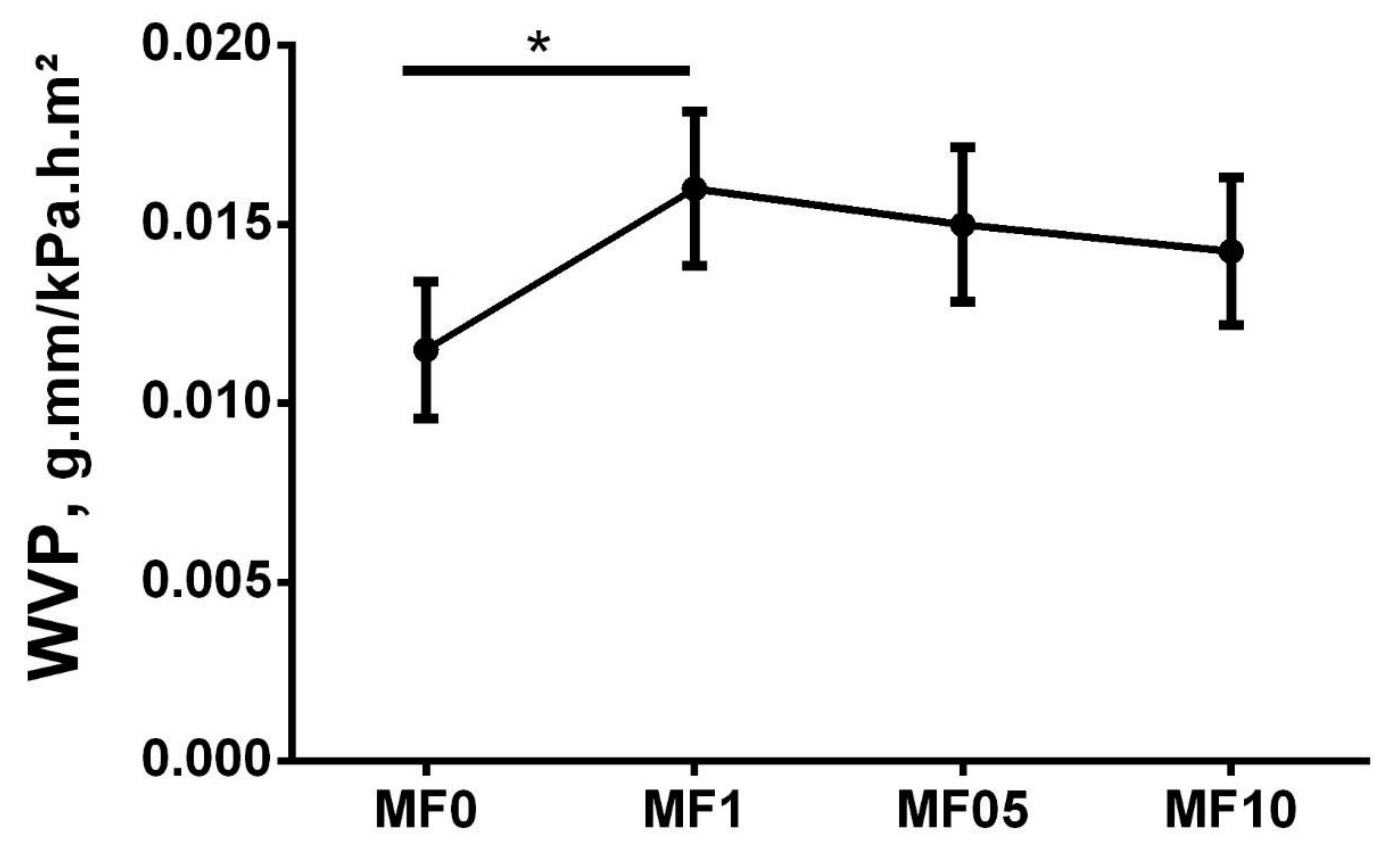


Supplementary Fig. S5. Frutalin-galactomannan hydrogels accelerate in vivo wound closure. Contraction of the excision wound 3 days after treatment with galactomannan-based hydrogel (F0) and the three different Frutalin-galactomannan hydrogel formulations (F01, F05 and F10). ${ }^{*} \mathrm{p}<0.01$ compared to the saline control (two-way ANOVA-Bonferroni test).

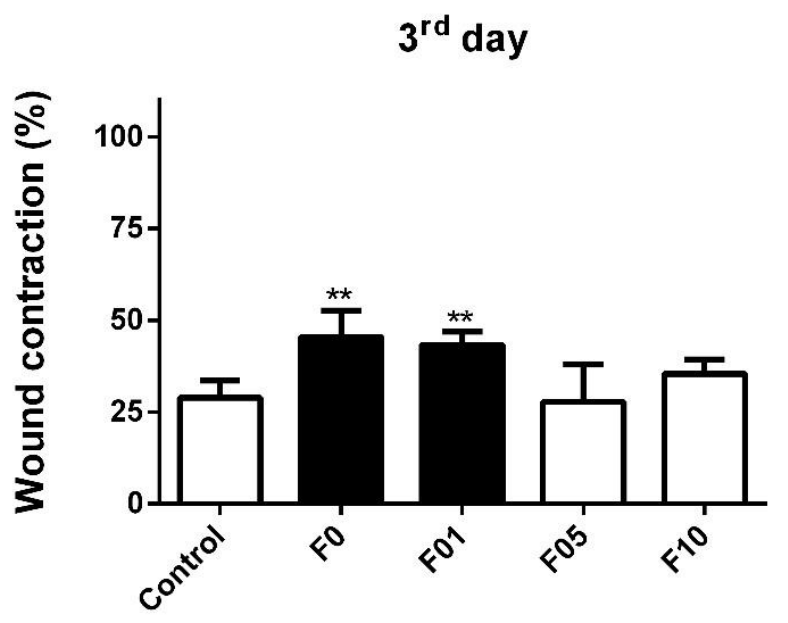

\section{Supplementary Fig. S6.}

In vivo wound closure with implanted spongy membrane scaffolds. Contraction of the excision wound 3 days is shown after treatment with galactomannan (MF0) plus three Frutalin-galactomannan (MF01, MF05 and MF10) membranes. $* *$ p $<0.01$ compared to the saline control (two-way ANOVA-Bonferroni test).

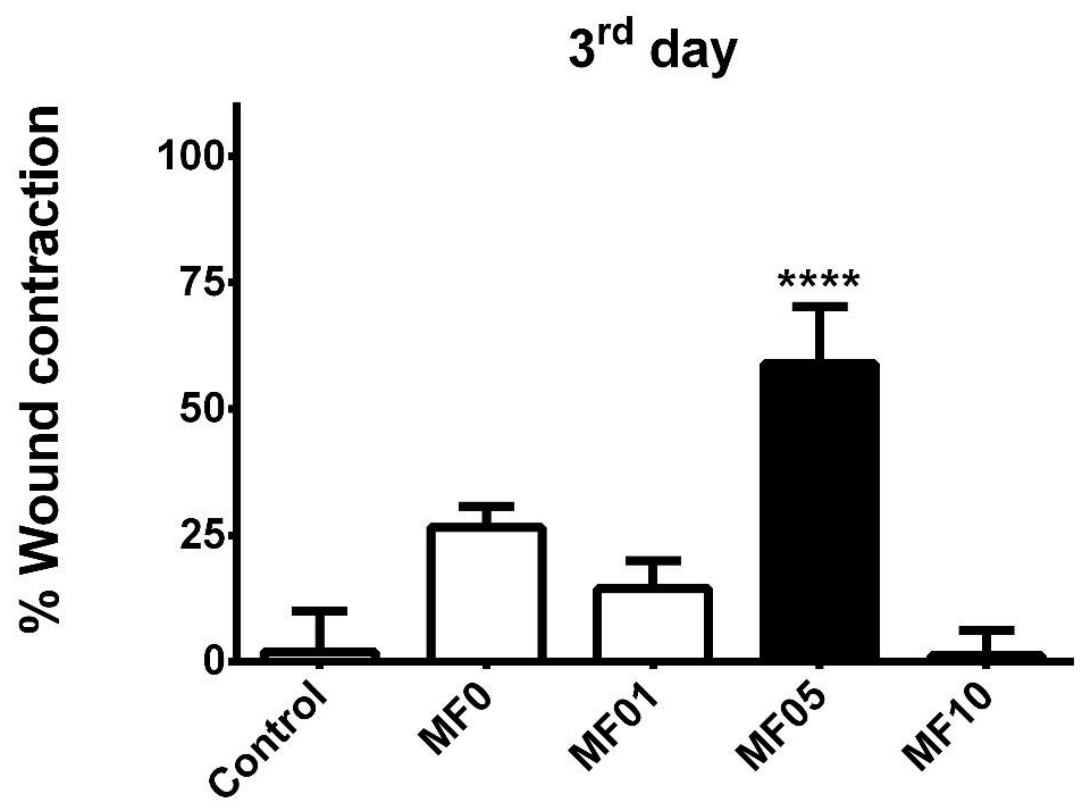

